\title{
Biglycan and Fibromodulin Have Essential Roles in Regulating Chondrogenesis and Extracellular Matrix Turnover in Temporomandibular Joint Osteoarthritis
}

\author{
Mildred C. Embree, ${ }^{* \dagger}$ Tina M. Kilts, ${ }^{*}$ \\ Mitsuaki Ono, ${ }^{*}$ Colette A. Inkson, ${ }^{*}$ \\ Fatima Syed-Picard, ${ }^{*}$ Morten A. Karsdal, ${ }^{\ddagger}$ \\ Åke Oldberg, ${ }^{\S}$ Yanming $\mathrm{Bi}^{*}{ }^{*}$ and Marian F. Young ${ }^{*}$ \\ From the Craniofacial and Skeletal Diseases Branch," National \\ Institutes of Dental and Craniofacial Research, National Institutes of \\ Health, Bethesda, Maryland; the Medical University of South \\ Carolina, College of Dental Medicine, ${ }^{\dagger}$ Charleston, South Carolina; \\ Nordic Biosciences, ${ }^{\ddagger}$ Herlev, Denmark; and the Department of \\ Experimental Medical Science, ${ }^{\S}$ Univeristy of Lund, Sweden
}

The temporomandibular joint is critical for jaw movements and allows for mastication, digestion of food, and speech. Temporomandibular joint osteoarthritis is a degenerative disease that is marked by permanent cartilage destruction and loss of extracellular matrix (ECM). To understand how the ECM regulates mandibular condylar chondrocyte (MCC) differentiation and function, we used a genetic mouse model of temporomandibular joint osteoarthritis that is deficient in two ECM proteins, biglycan and fibromodulin $\left(\mathrm{Bgn}^{-/ 0}\right.$ Fmod $^{-/-}$). Given the unavailability of cell lines, we first isolated primary MCCs and found that they were phenotypically unique from hyaline articular chondrocytes isolated from the knee joint. Using $\mathrm{Bgn}^{-/ 0}$ Fmod $^{-1-}$ MCCs, we discovered the early basis for temporomandibular joint osteoarthritis arises from abnormal and accelerated chondrogenesis. Transforming growth factor (TGF)- $\beta 1$ is a growth factor that is critical for chondrogenesis and binds to both biglycan and fibromodulin. Our studies revealed the sequestration of TGF- $\beta 1$ was decreased within the ECM of $\mathrm{Bgn}^{-/ 0} \mathrm{Fmod}^{-/-}$MCCs, leading to overactive TGF- $\beta 1$ signal transduction. Using an explant culture system, we found that overactive TGF- $\beta 1$ signals induced chondrogenesis and ECM turnover in this model. We demonstrated for the first time a comprehensive study revealing the importance of the ECM in maintaining the mandibular condylar cartilage integrity and identified biglycan and fibromodulin as novel key players in regulating chondrogenesis and
ECM turnover during temoporomandibular joint osteoarthritis pathology. (Am J Pathol 2010, 176:812-826; DOI: 10.2353/ajpath.2010.090450)

The temporomandibular joint (TMJ) is a unique articulating joint that is essential for proper mastication and verbal communication. Temporomandibular disorders encompass a group of complex and poorly understood conditions that are characterized by orofacial pain, joint sounds, and restricted joint movement. ${ }^{1}$ TMJ osteoarthritis $(\mathrm{OA})$ is the most prevalent and debilitating type of TMJ disorder, which causes severe pain, permanent tissue loss, and joint dysfunction. ${ }^{1,2}$ There are no standard diagnostic tests or treatments for this degenerative disease because of the limited understanding of the cellular and molecular mechanisms underlying TMJ biology and pathology. Therefore, comprehensive mechanistic studies may potentially contribute toward the development of diagnostic biomarkers and clinical therapies.

Currently, mechanistic studies on joint degenerative processes focus on other articular joints, such as the knee and hip. However, the mandibular condylar cartilage is distinct from other articular cartilages and possesses unique morphological, ${ }^{3}$ functional, ${ }^{4}$ biomechani$\mathrm{cal}^{5-7}$ and biological ${ }^{8-11}$ properties. For example, the articular zone is the most superficial cellular layer that uniquely distinguishes the TMJ as a fibrocartilage. Consequently, the superficial articular zone consists of type I collagen, ${ }^{11}$ whereas the remaining cellular zones below consist of type II collagen. ${ }^{12}$ On the other hand, the

Supported in part by the Intramural Research Program of the NIH, NIDCR, and by an F-30 training grant to the Medical University of South Carolina from the Extramural Program of the NIH, NIDCR (to support M.E.).

Accepted for publication September 29, 2009

Supplemental material for this article can be found on http://ajp. amjpathol.org

Address reprint requests to Marian Young, Ph.D., or Yanming Bi, Ph.D., Building 30 Room 225, MSC 4320, Craniofacial and Skeletal Diseases Branch, National Institute of Dental and Craniofacial Research, National Institutes of Heath, Bethesda, MD 20892. E-mail: myoung@dir.nidcr.nih.gov or ybi@nidcr.nih.gov. 
femoral head of the knee joint is constituted entirely of hyaline cartilage and type II collagen. ${ }^{8}$ Consequently, the cellular mechanisms underlying TMJ OA pathology may be different from other articular joints. However, no studies have been implemented to determine specific mechanisms regulating mandibular condylar chondrocytes (MCCs) because of the unavailability of cell lines and the difficulty of isolating primary MCCs. Therefore, it is critical to isolate MCCs to understand disease pathologies that are specific to the TMJ.

Cartilage tissue consists of chondrocytes and an abundant extracellular matrix (ECM) that primarily contains collagens, small and large proteoglycans, and water. Chondrocytes reside within the ECM and synthesize and maintain the ECM under normal conditions of low turnover. ${ }^{13}$ The ECM plays a critical role in the preservation of cartilage tissue integrity. In support of this idea, early stages of OA are marked by changes in the quantity, distribution, or composition of ECM, whereas late stages of $O A$ are marked by a gradual net loss of ECM components. ${ }^{14}$ Additionally, modifications in ECM collagens, such as type $\mathrm{VI}$ and type XI collagens, ${ }^{15,16}$ and small ECM proteoglycans, such as asporin, biglycan, and fibromodulin, ${ }^{17-19}$ can lead to the development of $\mathrm{OA}$ in the TMJ and in other joints. Furthermore, studies have reported that humans with genetic diseases involving defects in cartilage-related ECM genes, such as Marfan syndrome ${ }^{20}$ and Ehlers-Danlos syndrome, ${ }^{21}$ experience TMJ dysfunction. However, the precise role the ECM plays in regulating MCC function specifically within the TMJ remains largely unknown.

Biglycan (Bgn) and fibromodulin (Fmod) are members of the small leucine-rich repeat proteoglycan family (SLRPs) and are highly expressed in bone, tendon and cartilage. ${ }^{19,22}$ Mice deficient in Bgn and Fmod $\left(\mathrm{Bgn}^{-10}\right.$ $\mathrm{Fmod}^{-1-}$ ) develop OA in multiple joints, including the TMJ. ${ }^{18,19}$ Functionally, SLRPs can control ECM structure by interacting with the network of cartilage proteins and can mediate cell metabolism by binding to members of the transforming growth factor $\beta$ superfamily (TGF- $\beta$ ). ${ }^{17,23,24}$ Bgn and Fmod both bind to TGF- $\beta 1,{ }^{23}$ a potent growth factor that regulates the formation and degradation of the ECM and maintains cartilage integrity in murine and human articular cartilage. ${ }^{17,25-27}$

The goal of the present study was to understand how the ECM regulates the differentiation and function of MCCs. First, we isolated and characterized MCCs derived from mandibular condylar cartilage and hyaline articular chondrocytes (HACs) derived from knee hyaline articular cartilage. We show here that MCCs were phenotypically distinct from HACs, which underscores the importance for using MCCs specifically to study TMJ OA. Using genetically modified mice, we identified Bgn and Fmod as critical components of the ECM, which control the differentiation and function of MCCs by modulating TGF- $\beta 1$ activity. In the absence of Bgn and Fmod, TGF- $\beta 1$ sequestration within the ECM was decreased, leading to hypersensitive TGF- $\beta 1$ signaling. Increased TGF- $\beta 1$ signals accelerated both type II collagen and aggrecan production and degradation. Taken together, the absence of Bgn and Fmod ultimately led to an overall imbalance in ECM turnover and favored cartilage degradation and the onset of TMJ OA.

\section{Materials and Methods}

\section{Animals}

Male mice were used including $\mathrm{Bgn}^{-10} \mathrm{Fmod}^{-1-}$ mice and their strain-matched wild-type counterparts (C57BL/6129) with approval from the Animal Care and Use Committee, National Institutes of Health (\#NIDCR-DIR07-414). The generation of $\mathrm{Bgn}^{-10} \mathrm{Fmod}^{-1-}$ mice has been previously reported. ${ }^{19}$ Briefly, single-deficient mice were generated by targeted gene disruption in embryonic stem cells. ${ }^{28,29}$ The F1 generation of heterozygote mice was obtained by interbreeding a homozygous $\mathrm{Bgn}^{-1-} \mathrm{Fmod}^{+/+}$female with a homozygous $\mathrm{Bgn}^{+/ 0}$, $\mathrm{Fmod}^{-1-}$ male (Bgn is on the $\mathrm{X}$ but not $\mathrm{Y}$ chromosome). The F2 generation was subsequently obtained by interbreeding F1 heterozygote mice. All mice were genotyped for Bgn and Fmod by a PCR-based analysis using primers as described previously. ${ }^{19}$ The PCR products were resolved by electrophoresis through $1.8 \%$ agarose gels, yielding bands of $212 \mathrm{bp}$ for the wild-type Bgn allele, 310 bp for the disrupted Bgn allele, $280 \mathrm{bp}$ for the wild-type Fmod allele, and 603 bp for the disrupted Fmod allele.

\section{Cell Isolation and Culture}

TMJ condylar cartilages and knee articular cartilage were dissected from 6- to 8-week-old mice and digested with 3 $\mathrm{mg} / \mathrm{ml}$ collagenase type I (Worthington Biochem, Freehold, NJ) and $4 \mathrm{mg} / \mathrm{ml}$ dispase (Roche) in 1X PBS for 3 hours at $37^{\circ} \mathrm{C}$. Single cell suspensions were cultured $(5 \%$ $\mathrm{CO}_{2}, 37^{\circ} \mathrm{C}$ ) in basal medium consisting of $\alpha$-MEM (Gibco), supplemented with $20 \%$ lot selected fetal bovine serum (Equitech-bio, Inc), 2 mmol/L glutamine, $100 \mathrm{U} / \mathrm{ml}$ penicillin $100 \mathrm{mg} / \mathrm{ml}$ streptomycin (Biofluids), and 100 $\mathrm{mmol} / \mathrm{L} 2$ 2- mercaptoethanol (Gibco) for four to six days. The cells were detached with trypsin-EDTA (GIBCO) and plated for the in vitro experiments as described below for each assay.

\section{Proliferation of MCCs}

The proliferation of MCCs was measured using a cell proliferation bromo-2'-deoxyuridine (BrdU) ELISA Chemiluminescent kit (Roche) according to the manufacturer's instructions. MCCs $\left(3 \times 10^{4}\right.$ per well, passage 1$)$ were plated into 96-well black plates with clear bottoms (BD Biosciences Labware) to minimize background and to allow for microscopic visualization of the cells during incubation. MCCs were cultured $\left(5 \% \mathrm{CO}_{2}, 37^{\circ} \mathrm{C}\right)$ overnight in basal medium and were labeled with BrdU labeling reagent for 2 hours. After removing the labeling reagent, MCCs were fixed and the anti-BrdU antibody was added. After substrate reaction, the immune complexes that formed were detected and quantified using a scanning multiwell luminometer. 


\section{Immunocytochemistry}

MCCs or HACs $\left(5 \times 10^{4}\right.$ per well, passage 1$)$ were plated onto 12-well plates containing 18-mm coverslips and cultured $\left(5 \% \mathrm{CO}_{2}, 37^{\circ} \mathrm{C}\right)$ overnight in basal medium. Cells were fixed with $4 \%$ paraformaldehyde for 20 minutes at room temperature, permeablized with 5\% DMSO, 0.25\% Triton-X in PBS for 5 minutes, and treated with primary antibodies for 1 hour at room temperature. The broadspectrum immunoperoxidase AEC kit (Picture Plus, Zymed) was subsequently used to detect the immunoactivity according to the manufacturer's instructions. Primary antibodies used in this study included polyclonal rabbit anti-human type I collagen (1:2000 dilution, rabbit antiserum, LF-68, Dr. Larry Fisher at NIH), monoclonal mouse anti-mouse type II collagen (1:50, $4 \mathrm{mg} / \mathrm{ml}$, mouse $\lg G_{1}$, cat\# ECM1400N; Chemicon), polyclonal rabbit antimouse aggrecan $(1: 100,5 \mathrm{mg} / \mathrm{ml}$, rabbit $\mathrm{lgG}$, cat \# AB1031; Chemicon), and mouse anti-human Smad4 (mouse lgG 1 1:100, $200 \mathrm{mg} / \mathrm{ml}$, cat \# sc-73599, Santa Cruz). Isotype- matched antibodies were used as negative controls under the same conditions. The cells were counterstained with hematoxylin.

\section{Pellet Cultures}

Cells $\left(5 \times 10^{5}\right.$, passage 1$)$ were pelleted in $15 \mathrm{ml}$ polypropylene tubes by centrifugation and cultured $\left(5 \% \mathrm{CO}_{2}\right.$, $37^{\circ} \mathrm{C}$ ) for 3 weeks in Dulbecco's Modified Eagle medium (DMEM) supplemented with $10^{-7} \mathrm{~mol} / \mathrm{L}$ dexmethasone, $100 \mu \mathrm{mol} / \mathrm{L}$ ascorbic acid, 1\% insulin, transferrin, selenium (ITS), $1 \mathrm{mmol} / \mathrm{L}$ pyruvate, and $1 \mathrm{ng} / \mathrm{ml}$ TGF- $\beta 1$ containing previously described. ${ }^{22}$ Pellets were prepared for histology and real-time RT-PCR.

\section{Real-Time RT-PCR}

Total RNA was isolated from confluent MCCs and HACs, pellet cultures, or whole mandibular condyles using Trizol (Invitrogen). Samples were treated using a RNase-free DNase removal reagent (Ambion). cDNA was obtained by reverse transcribing total RNA with TaqManTM reverse transcription reagents (Applied Biosystems). Primers were designed using Beacon Designer Software (Biorad) and included the following: Comp, forward 5'-CGCAGCTGCAAGACGTGAGAGAGCTGT-3', reverse 5'-CCGAATTCCGCTGGTCTGGGTTTCGA-3'; Sox9, forward 5'-TCAGATGCAGTGAGGAGCAC-3', reverse 5'-CCAGCCACAGCAGTGAGTAA-3'; ADAMTS4, forward 5'-CGCTGACCGCCAATGCCAACTG-3', reverse 5'-GCCCAAGGTGAGTGCTTCGTCTG-3'; ADAMTS5, forward 5'-TCCCGAGGAACTCCCAGGACAGAC-3', reverse 5'-CGCACCACAGCACACCACAGC-3'; Gapdh, forward 5'-GAGAGGCCCTATCCCAACTC-3', reverse 5'-GTGGGTGCAGCGAACTTTAT-3'; Sox5, forward 5'-GCTGTCACCAAGGCAATCCAAGAAG-3', reverse 5'-TGCTGAGACCTATGCTGTTCACCAC-3'; Sox6, forward 5'-AAAGGAAACCACAGGCAAGGGAAGC-3', reverse 5'-CAGCAGCAGCGTTCACGAGCAG-3'; Col2A1, forward 5'-CGAGGGCAACAGCAGGTTCACATAC-3', reverse 5'-GTCAATAATGG-
GAAGGCGGGAGGTC-3'; Col1A1, forward 5'-CACCCTCAAGAGCCTGAGTC-3', reverse 5'-GCTTCTTTTCCTTGGGGTTC-3'; Col10A1, forward 5'-GGGATGCCGCTTGTCAGTGCTAAC-3', reverse 5'-TGGGTCGTAATGCTGCTGCCTATTG-3'; S29 forward 5'-GGAGTCACCCACGGAAGTTCG-3', reverse 5'-GGAAGCAGCTGGCGGCACATG-3'. Real-time PCR was performed using primers, SYBR-green PCR Master Mix (Applied Biosystems), and a Biorad MyIQ real-time PCR thermocycler. Each cDNA (5-10 ng) was amplified with an initial denaturation at $95^{\circ} \mathrm{C}$ for 10 minutes, then $95^{\circ} \mathrm{C}$ for 15 seconds and $65^{\circ} \mathrm{C}$ for 30 seconds, for 40 cycles. Gene expression was normalized to the housekeeping gene S29. Melt-curve analysis was routinely run, and the PCR reactions were also analyzed by gel electrophoresis to confirm that a single product of the expected size was amplified.

\section{TGF- $\beta 1$ ELISA}

MCCs $\left(5 \times 10^{4}\right.$ per well, passage 1$)$ were plated into the wells of a 24 -well plate and cultured to confluence $(5 \%$ $\mathrm{CO}_{2}, 37^{\circ} \mathrm{C}$ ). The cells were cultured in serum-free medium overnight and treated with or without $1 \mathrm{ng} / \mathrm{ml}$ TGF- $\beta 1$ for 30 minutes. The culture medium was collected and active TGF- $\beta 1$ concentrations were determined by TGF- $\beta 1$ ELISA (R\&D Systems). The sequestration of active TGF- $\beta 1$ was determined as previously described. ${ }^{24}$

\section{Western Blotting}

MCCs $\left(2 \times 10^{5}\right.$ per well, passage 1$)$ were plated into the well of a 6-well plate until confluent. MCCs were cultured in serum-free medium overnight, and then treated with 1 $\mathrm{ng} / \mathrm{ml}$ TGF- $\beta 1$ (R\&D) or vehicle for 30 minutes. The protein extraction and Western blot analyses were performed as previously described. ${ }^{24}$ The primary antibodies included: rabbit anti-p-Smad2, -Smad2 (1:500, Cell Signaling), and rabbit anti-Hsp 90 (1:500, Santa Cruz).

\section{Nucleofection and Luciferase Reporter Assays}

Activation of the TGF- $\beta 1$ signaling pathway was determined using a TGF- $\beta 1$ responsive luciferase reporter, SBE-luc. This construct is a Smad2/3-responsive luciferase reporter construct and was a kind gift from Dr. Reegis O'Keefe, Rochester University, Rochester, NY. Transient transfection of MCCs was performed using the Nucleofector system (Amaxa, Germany) and the mesenchymal stem cells transfection kit with modification. Optimal transfection conditions were first determined using a construct containing green fluorescent protein (GFP), to achieve approximately $60 \%$ to $80 \%$ transfection efficiency for approximately 72 hours. MCCs $\left(5 \times 10^{5}\right.$ cells, passage 2) were placed in transfection solution with $2 \mu \mathrm{g}$ total DNA, and subjected to electroporation using the program C-17. phSV40 renilla luciferase construct (SBEluc: phSV40 $=20: 1)$ was used as an internal control. pGL3 vector served as an empty vector control. The transfected cells were split into three wells of 96-well 
plates and cultured for 24 hours. Luciferase activity was measured using the dual reporter assay system (Promega, Madison, WI). Luciferase activity was normalized to relative renilla activity within the same well.

\section{Explant Cultures}

Mandibular condyles were harvested from 5-week-old mice, dissected in half, weighed, and cultured in a 24well plate (Corning, cat\# 3527) in DMEM supplemented with $100 \mathrm{mmol} / \mathrm{L}$ ascorbic acid for 24 hours. The left mandibular condyles were treated with $2 \mathrm{ng} / \mathrm{ml}$ TGF- $\beta 1$, and the right mandibular condyles were treated with vehicle control. The metabolically inactivated explants served as additional baseline control, which were created with three repeated freeze-thaw cycles in liquid N2 and a $37^{\circ} \mathrm{C}$ water bath. After two days, the media in mandibular condylar explant cultures were collected for CTX II, FFGVG and zymogram assays. The explants were prepared for histology and real-time RT-PCR.

\section{Detection of Matrix Metalloprotease-Derived Type II Collagen Fragment CTX-II}

CTX-II fragments released in explant culture medium were measured using RatLaps ELISA kit (Nordic Bioscience Diagnostics) according to the manufacturer's instructions.

\section{Detection of Matrix Metalloprotease-Derived Aggrecan Fragment ${ }^{342}$ FFGVG-G2}

The ${ }^{342}$ FFGVG-G2 fragments released in the explant culture medium were measured using an ELISA as previously developed and described. ${ }^{30}$ Two monoclonal antibodies were used in a sandwich ELISA, including antibody AF- $28^{31}$ recognizing ${ }^{342}$ FFGVG-G2 fragment and antibody, F78 ${ }^{30}$ recognizing epitopes within the G1 and G2 globular domains of aggrecan.

\section{Zymography}

Matrix metalloprotease (MMP) activity of mandibular condylar explant culture medium $(5 \mathrm{ml})$ was determined by using $10 \%$ Tris-glycine gels with $0.1 \%$ gelatin incorporated as a substrate (Invitrogen) according to the manufacturer's instructions.

\section{Histology and Immunohistochemistry}

Paraffin-embedded sections were dewaxed in xylene washes and rehydrated through graded ethanol $(100 \%$, $95 \%$, and $75 \%$ ) and water. Tissue sections were stained histochemically with hematoxylin and eosin (H\&E), toluidine blue, or Safranin O. A semiquantitative histological scoring system, based on a modified Mankin system, ${ }^{32}$ was used to investigate degenerative changes in the mandibular condylar cartilage. Comparable H\&E sections from wild-type and $\mathrm{Bgn}^{-10} \mathrm{Fmod}^{-1-}$ mice were divided into artic- ular, mature, and hypertrophic zones based on cell morphology. The area and number of cells within each cellular zone was computed using the Visiopharm Integrator System imaging software (MUSC Center for Oral Health Research Core Facility, Charleston, SC).

For immunohistochemistry, rehydrated sections were enzymatically treated with $\mathrm{ABC}$ ase and incubated with primary antibodies at $4^{\circ} \mathrm{C}$ overnight, including polyclonal rabbit anti-mouse Bgn (1:500 dilution, rabbit total serum, LF106; Dr. Larry Fisher, $\mathrm{NIH}$ ), polyclonal rabbit anti-mouse Fmod (1:500 dilution, rabbit total serum, LF-149; Dr. Larry Fisher, $\mathrm{NIH})$, polyclonal rabbit anti-human type I collagen (1:2000 dilution, rabbit antiserum, LF-68; Dr. Larry Fisher, $\mathrm{NIH}$ ), monoclonal mouse anti-mouse type II collagen (1: 200, 1 mg/ml, mouse lgG 1 , cat\# ECM1400N; Chemicon), polyclonal rabbit anti-mouse aggrecan $(1: 100,5 \mathrm{mg} / \mathrm{ml}$, rabbit IgG, cat \# AB1031; Chemicon), polyclonal rabbit anti-type $X$ collagen (1:1000 dilution, rabbit total serum; Dr. Lunstrum, Shriners Hospital, Portland, OR), polyclonal rabbit anti-Comp (1:1000, total rabbit serum; Dr. Dick Heinegard, University of Lund, Sweden), and monoclonal mouse anti-mouse TGF- $\beta 1$ (mouse IgG1, cat\#MAB240; R\&D Systems). Isotype-matched antibodies were used as negative controls under the same conditions. The broadspectrum immunoperoxidase AEC kit (Picture Plus, Zymed) was subsequently used to detect the immunoactivity according to the manufacturer's instructions. The sections were counterstained with hematoxylin. The area of positive immunostaining was computed using the Visiopharm Integrator System imaging software (MUSC Center for Oral Health Research Core Facility, Charleston, SC).

\section{Glycosaminoglycan Assay}

The relative level of total glycosaminoglycans (GAG) present in the condylar cartilage was determined using a Blyscan kit (Biocolor). Condyles were dissected from wild-type and $\mathrm{Bgn}^{-10} \mathrm{Fmod}^{-1-}$ mice at 12 and 36 weeks. To liberate GAGs from the extracellular matrix, samples were digested with $20 \mathrm{mg} / \mathrm{ml}$ protease $\mathrm{K}$ with vigorous shaking overnight at $55^{\circ} \mathrm{C}$. The GAG assay was performed following the manufacturer's instructions, and the relative quantity of GAG was obtained by measuring absorbance at A650. The absorbance was normalized to the mass of each sample.

\section{Statistical Analysis}

We reported representative data of at least three independent experiments unless otherwise indicated. We performed statistical analyses with Student $t$ test.

\section{Results}

\section{Mandibular Condylar Chondrocytes Are Phenotypically Unique from Knee Hyaline Articular Chondrocytes}

MCCs and HACs were isolated in parallel by digesting minced mandibular condyle or knee joint hyaline articular 


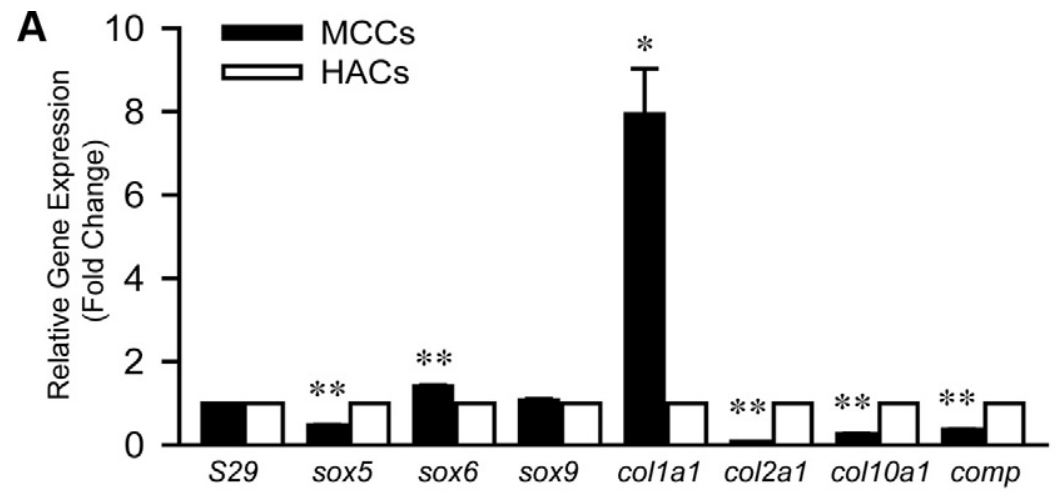

B

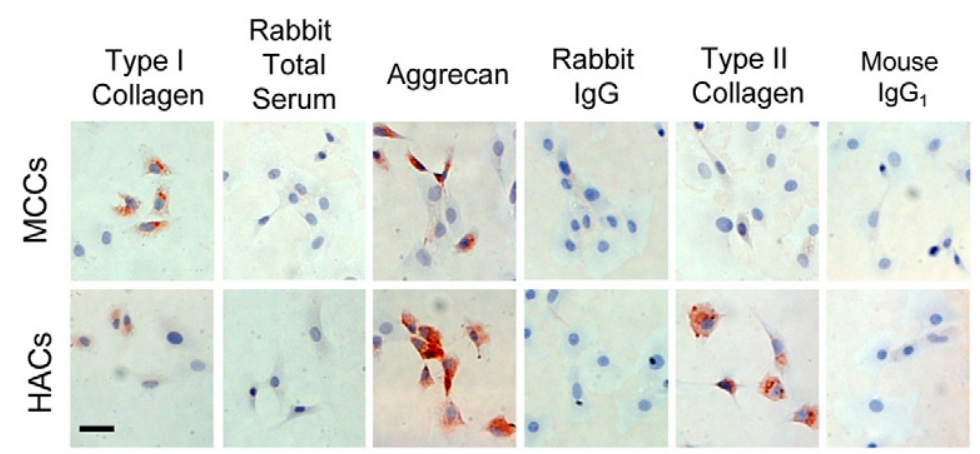

C

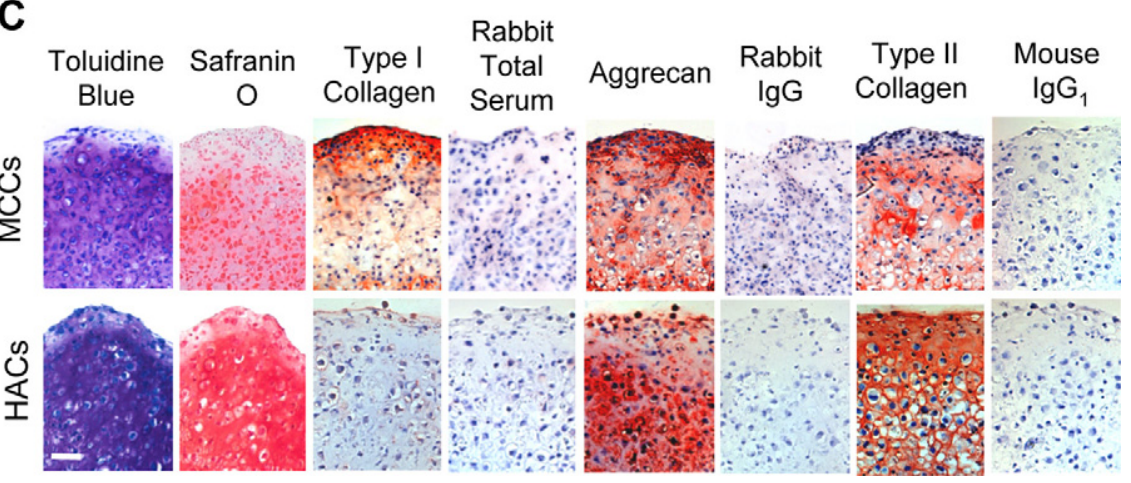

Figure 1. Comparison of mandibular condylar chondrocytes (MCCs) and hyaline articular chondrocytes (HACs). A: Quantitative real-time RT-PCR analysis of cartilage-related genes sox 5 , sox6, sox 9, col1a1, col2a1, col10a1, and comp using total RNA isolated from HACs (open bars) and MCCs (black bars). Gene expression was normalized to the housekeeping gene S29. The expression of genes in MCCs was relative to that of HACs. Data are mean \pm SEM of 2 experiments. ${ }^{*} P<0.02$, ${ }^{* *} P<0.006$ MCCs versus HACs. B: Immunocytochemistry staining of cartilage-related proteins type I collagen, aggrecan, and type II collagen in MCCs and HACs. Rabbit total serum, rabbit IgG, and mouse $\operatorname{IgG}_{1}$ were used under the same conditions as negative controls, respectively. Scale bar $=50 \mu \mathrm{m}$. C: Chondrogenic differentiation of HACs and MCCs. Chondrogenic differentiation was induced by culturing pelleted HACs or MCCs in chondrogenic induction medium for 3 weeks and was assessed by toluidine blue and Safranin O staining. The expression of type I collagen, aggrecan, and type II collagen was assessed by immunhistochemistry. Rabbit total serum, rabbit $\mathrm{IgG}$, and $\mathrm{mouse}_{\mathrm{IgG}}$ were used under the same conditions as negative controls, respectively. Scale bar $=50 \mu \mathrm{m}$ cartilage with dispase II and type I collagenase. The cells were expanded and examined for similarities and differences in their phenotypic traits in vitro. Real time RT-PCR showed differential expression of chondrogenic-related genes. MCCs expressed higher levels of Sox6 and type I collagen (Col 1a1), whereas HACs expressed higher levels of Sox5, type II collagen ( $\mathrm{Col} 2 \mathrm{a}$ ), type X collagen ( $\mathrm{Col}$ 10a1), and cartilage oligomeric protein (Comp, Figure 1A). These data indicate that although MCCs share molecular overlap with HACs, MCCs have unique gene expression patterns that are different from HACs.

Chondrocytes isolated from the knee hyaline articular cartilage are heterogeneous. ${ }^{33}$ To determine the heterogeneity of MCCs, immunocytochemistry was performed (Figure 1B). MCCs had more precursor cells than HACs, where the percentage of type I collagen immuno-positive cells (73 $\pm 8 \%$ versus $44 \pm 3 \%$ ) was significantly higher (data are mean \pm SD of 6 random fields, $P<0.004$ MCCs versus HACs). MCCs had less differentiated cells in comparison with HACs, where the percentage of aggrecan (27 $\pm 8 \%$ versus $60 \pm 11 \%)$ and type Il collagen ( $1 \pm 1 \%$ versus $65 \pm 11 \%$ ) immuno-positive cells was significantly lower (data are mean $\pm \mathrm{SD}$ of $6-9$ random fields, $P<$ $0.001 \mathrm{MCC}$ versus HACs). Interestingly, these in vitro findings corresponded with the in vivo observations that type I collagen is expressed in fibrocartilage, but not in hyaline cartilage. ${ }^{4}$ Taken together, these data demonstrated that isolated MCCs are distinct heterogeneous cells that reflect the unique in vivo tissues from which the cells are derived.

To test whether MCCs were able to undergo chondrogenesis in a manner similar to HACs, both MCCs and HACs were expanded and induced to undergo chondrogenesis in a three-dimensional pellet culture system. Like HACs, MCCs formed a cartilage-like structure that deposited abundant proteoglycans visualized by staining for toluidine blue, Safranin $O$, and immunostaining for aggrecan expression (Figure 1C), although the intensity was lower compared with the HAC pellets. MCCs were able to undergo mature stages of differentiation and expressed copious amounts of type II collagen in pellet cultures (Figure 1C). Unlike HAC pellets, MCC pellets 
produced type I collagen but not type X collagen (Figure $1 C)$. Therefore, MCC pellets are likely in an earlier stage of differentiation. Interestingly, type I collagen expression was localized within the superficial layer of MCC pellets, which is similar to the type I collagen expression pattern in the superficial fibrocartilagenous layer of the mandibular condylar cartilage. ${ }^{12}$ Taken together, these data show that MCCs shared some molecular overlap with HACs, but were also distinct and appeared to retain their fibrocartilage nature in pellet cultures after they were isolated and expanded in vitro. Therefore, MCCs are a more appropriate cell type for studying the cellular events contributing to TMJ pathology.

\section{Mandibular Condylar Chondrocytes Show Abnormal Growth and Differentiation in the Absence of Bgn and Fmod}

To understand the mechanisms underlying the TMJ pathology, we used a previously established TMJ OA mouse model. ${ }^{18}$ This mouse model is deficient in two small proteoglycans, Bgn and Fmod that are highly expressed in the articular and mature zones in the mandibular condylar cartilage and in MCCs derived from this tissue (supplemental Figure S1A at $h$ ttp://ajp.amjpathol.org). At 24 weeks, $\mathrm{Bgn}^{-10}$ $\mathrm{Fmod}^{-1-}$ mice demonstrated considerable histological and morphological changes in the mandibular condyle (see supplemental Figure S1B at http://ajp.amjpathol.org). The mandibular condyle shape was dysmorphic, and the articulating surface of the condyle appeared flattened (yellow arrows) in the $\mathrm{Bgn}^{-10} \mathrm{Fmod}^{-1-}$ mice compared with the wild-type mice. We noted by histology that the $\mathrm{Bgn}^{-10}$ $\mathrm{Fmod}^{-1-}$ mandibular condylar cartilage had increased cellularity compared with wild-type cartilage and had expanded articular and mature zones (supplemental Figure S1A at $h$ ttp://ajp.amjpathol.org). This could be attributable to increased proliferation and/or survival of MCCs. However, we previously showed that the apoptosis of chondrocytes in the mandibular condyle increased in the absence of Bgn and Fmod. ${ }^{34}$ Therefore, the hypercellularity was likely attributable to increased proliferation of MCCs. To test this, we determined the cell proliferation rate by measuring BrdU incorporation using a BrdU ELISA assay after wild-type MCCs and $\mathrm{Bgn}^{-10} \mathrm{Fmod}^{-1-}$ MCCs were cultured for 3 days. The results showed that the proliferation of $\mathrm{Bgn}^{-10} \mathrm{Fmod}^{-1-}$ MCCs was 2.7-fold higher than wild-type MCCs (supplemental Figure S2A at $h$ ttp://ajp.amjpathol.org). Similarly, proliferation in the mandibular condylar cartilages of 3-day-old $\mathrm{Bgn}^{-10} \mathrm{Fmod}^{-1-}$ mice was 3.2-fold higher than wild-type mice (supplemental Figure S2B at $h$ ttp://ajp.amjpathol.org). Thus, the proliferation of MCCs was increased in the absence of Bgn and Fmod.

To test the effect of Bgn and Fmod on chondrogenesis, we first compared the expression of chondrogenic markers in MCCs from 3-week-old wild-type and $\mathrm{Bgn}^{-10}$ $\mathrm{Fmod}^{-1-}$ mice. Real-time RT-PCR showed that genes critical for chondrogenesis, including sox9, agg, col2a1, and col10a1, were up-regulated in the $\mathrm{Bgn}^{-10} \mathrm{Fmod}^{-1-}$ MCCs (Figure 2A, left). Immunocytochemistry revealed that the expression of aggrecan and type II collagen- positive cells in $\mathrm{Bgn}^{-10} \mathrm{Fmod}^{-1-} \mathrm{MCC}$ s were 1.6-fold and 4.2-fold higher than wild-type MCCs, respectively (Figure $2 \mathrm{~A}$, right). MCCs were next used to examine chondrogenesis in pellet cultures for 3 weeks. Real-time RT-PCR using mRNA extracted from pellets showed that agg, col2a1, and col10a1 gene expression levels were all increased in $\mathrm{Bgn}^{-10} \mathrm{Fmod}^{-1-}$ pellets compared with wildtype pellets (Figure 2B, left). These data suggested that $\mathrm{Bgn}^{-10} \mathrm{Fmod}^{-1-}$ pellets may be at a later stage of differentiation than wild-type pellets. Histological analysis revealed intense toluidine blue and Safranin O staining, suggesting a relatively higher amount of proteoglycan deposition in the ECM of the $\mathrm{Bgn}^{-10} \mathrm{Fmod}^{-1-}$ pellet (Figure 2B, right) Immunohistochemical analysis showed increased type I collagen, type II collagen, and aggrecan in $\mathrm{Bgn}^{-10} \mathrm{Fmod}^{-1-}$ pellets. Type X collagen, a marker for chondrocyte terminal differentiation, was expressed in the $\mathrm{Bgn}^{-10} \mathrm{Fmod}^{-1-}$ pellets, but not expressed in wildtype pellets. Therefore, the increased content of chondrogenic related proteins in $\mathrm{Bgn}^{-10} \mathrm{Fmod}^{-1-}$ pellets was likely attributable to increased expression rather than decreased degradation of those proteins. Consistent with this observation, type II collagen expression was expanded in the mandibular condylar cartilage of 3-weekold $\mathrm{Bgn}^{-10} \mathrm{Fmod}^{-1-}$ mice shown by immunohistochemistry staining (Figure 2C, left, arrows). Furthermore, type II collagen was localized more distally from the articular surface in $\mathrm{Bgn}^{-10} \mathrm{Fmod}^{-1-}$, which indicated that the articular zone was expanded. Furthermore, real-time RTPCR (Figure 2C, right) using RNA extracted from the condyles of 3-week-old mice, showed higher levels of type II collagen (col2a1), aggrecan (agg), and type X collagen (col10a1) in $\mathrm{Bgn}^{-10} \mathrm{Fmod}^{-1-}$ mice. Overall, our data suggested that the $\mathrm{Bgn}^{-10} \mathrm{Fmod}^{-1-}$ MCCs have an increased propensity to differentiate. Therefore, suppressed chondrogenesis is not likely a contributing factor in $\mathrm{Bgn}^{-10} \mathrm{Fmod}^{-1-}$ TMJ OA pathology.

\section{Loss of Aggrecan Content in Mandibular Condylar Cartilage Is Accelerated in the Absence of Bgn and Fmod}

Given that aggrecan loss is a major contributor to cartilage degeneration in other joints, ${ }^{35}$ we examined changes in proteoglycan content and the progression of osteoarthritic changes with aging. H\&E staining revealed the articular and mature zones were expanded in the $\mathrm{Bgn}^{-10} \mathrm{Fmod}^{-1-}$ mice at 3 and 5 weeks (Figure 3A, yellow arrows). Quantitative evaluation of histology confirmed that the area and the number of cells in the articular and mature zones were significantly increased $\mathrm{Bgn}^{-1}$ ${ }_{\text {oFmod }}{ }^{-1-}$ mice at 3 and 5 weeks, but no differences in area or cell number within the hypertrophic zone were found (supplemental Table S1 at http://ajp.amjpathol.org). Immunohistochemical staining revealed that aggrecan was more intense and expanded (Figure 3A, black arrows) in $\mathrm{Bgn}^{-10} \mathrm{Fmod}^{-1-}$ mice at 3 weeks of age compared with wild-type mice. Parallel changes were noted for the expression of type II collagen, where its immunoreactivity was more intense, localized more distal from 
A
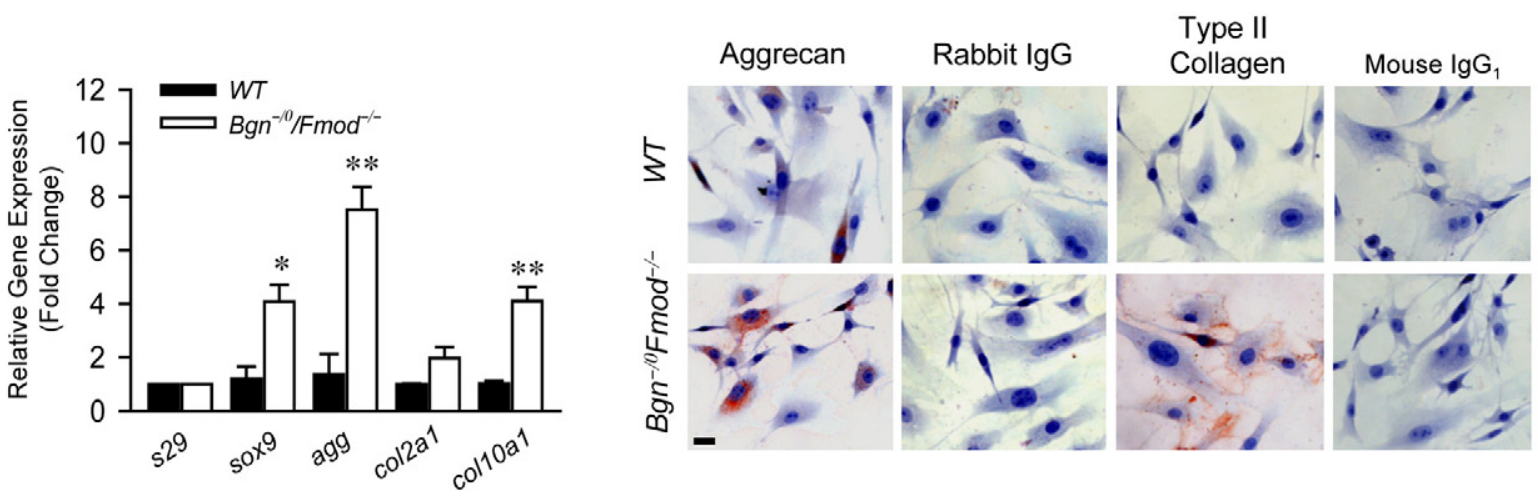

B
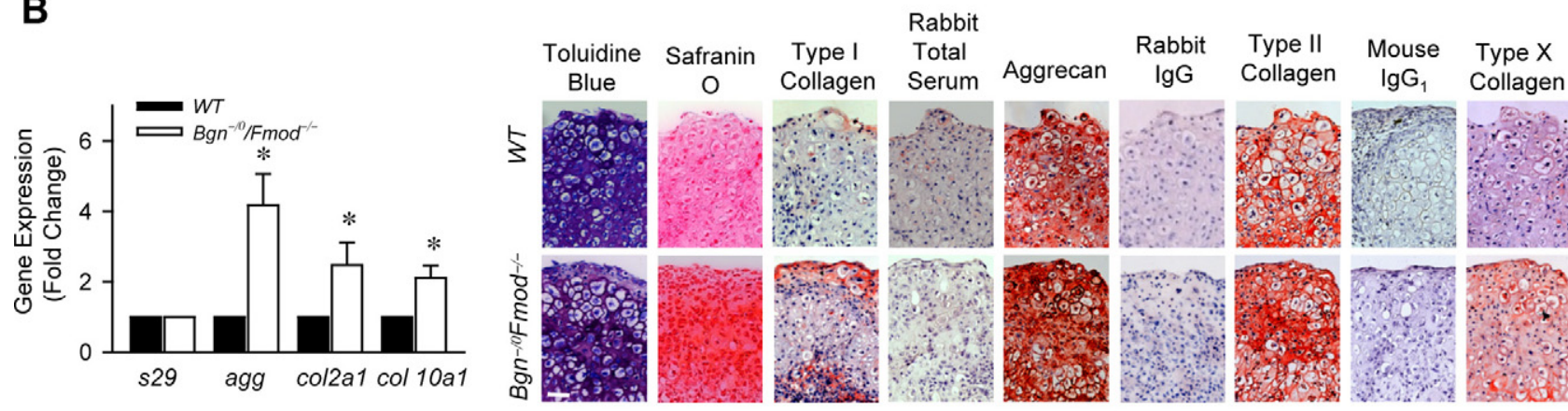

C

$\mathrm{Bgn}^{-10}$
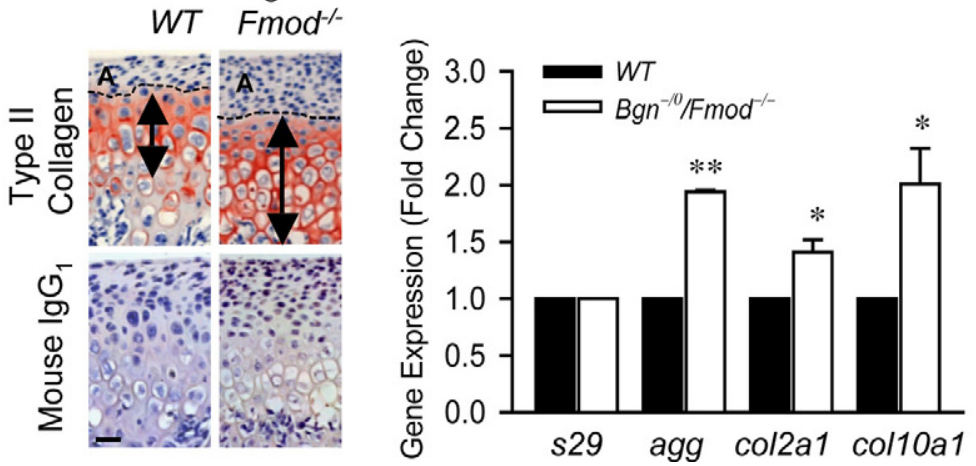

Figure 2. Increased chondrogenesis in the absence of Bgn and Fmod. A: Quantitative real-time RT-PCR analysis compared the expression levels of chondrogenicrelated genes using total RNA isolated from in wild-type (WT) and $B g n^{-10} \mathrm{Fmod}^{-1-}$ MCCs (left). Gene expression was normalized to the housekeeping gene S29. The expression of genes in wild-type MCCs was relative to that in $B g n^{-/ 0} \mathrm{Fmod}^{-1-}$ MCCs. Data are mean \pm SEM of 3 experiments. ${ }^{*} P<0.02,{ }^{* *} P<0.006$

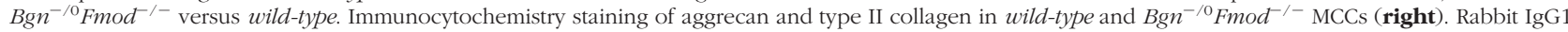
and mouse $\operatorname{IgG}_{1}$ were used as negative controls, respectively. Scale bar $=20 \mu \mathrm{m}$. B: Chondrogenesis of MCCs was induced by culturing pelleted wild-type and $B g n^{-/ 0} \mathrm{Fmod}^{-1-}$ MCCs in chondrogenic induction medium for 3 weeks. Real-time RT-PCR analysis of chondrogenic-related genes using total RNA isolated from wild-type and $\mathrm{Bgn}^{-/ 0} \mathrm{Fmod}^{-1-}$ pellets (left). Gene expression was normalized to the housekeeping gene S29. The expression of genes in wild-type pellets was relative to that in $\mathrm{Bgn}^{-/ 0} / \mathrm{Fmod}^{/-}$pellets. Data are mean \pm SEM of 2 experiments. ${ }^{*} \mathrm{P}<0.09 \mathrm{Bgn}^{-/ 0} \mathrm{Fmod}^{/-}$versus wild-type. Pellets were assessed by toluidine blue and Safranin O staining. The expression of type I collagen, aggrecan, type II collagen, and type X collagen were examined by immunohistochemistry (right). Scale bar $=50 \mu \mathrm{m}$. Rabbit total serum, rabbit IgG, and mouse IgG I $_{1}$ were used under the same conditions as negative controls. $\mathbf{C}$ : Type II collagen expression was assessed by immunohistochemistry in the mandibular condylar cartilage of 3-week-old wild-type and $\mathrm{Bgn}^{-/ 0} \mathrm{Fmod}^{-1-}$ mice (left). Arrows indicate the position and extent of type II collagen expression. Mouse IgG $_{1}$ was used under the same conditions as a negative control. Scale bar $=50 \mu \mathrm{m}$. Real-time RT-PCR analysis was used to compare the expression chondrogenenic-related genes Using total RNA isolated from the mandibular condylar cartilages of 3-week-old wild-type and $\mathrm{Bgn}^{-/ 0} \mathrm{Fmod}^{-/-}$mice (right). Gene expression was normalized to the housekeeping gene S29. The expression of individual genes in wild-type mandibular condylar cartilage was relative to that in $\mathrm{Bgn}^{-/ 0} \mathrm{Fmod}^{-/-}$mandibular condylar cartilage. Data are mean \pm SEM of 3 experiments. ${ }^{*} P<0.003$, ${ }^{* *} P<$ $0.0001 \mathrm{Bgn}^{-/ 0} \mathrm{Fmod}^{/-}$versus wild-type.

the articular surface, and slightly expanded in the $\mathrm{Bgn}^{-10}$ $\mathrm{Fmod}^{-1-}$ mice. With aging, aggrecan content rapidly decreased in mandibular condylar cartilage and was localized mainly in the hypertrophic zone (Figure 3A, 3, 5, and 24 weeks). Quantitative evaluation confirmed that the area of aggrecan immunostaining was significantly decreased in the $\mathrm{Bgn}^{-10} \mathrm{Fmod}^{-1-}$ mandibular condylar cartilages compared with wild-type mandibular condylar cartilages on aging (supplemental Table $\mathrm{S} 1$ at http:// ajp.amjpathol.org). We speculated that the accelerated loss of aggrecan content in $\mathrm{Bgn}^{-10} \mathrm{Fmod}^{-1-}$ mandibular condylar cartilage could be attributable to increased degradation of this protein, because the ability of MCCs to express aggrecan was not compromised in $\mathrm{Bgn}^{-10}$ Fmod $^{-1-}$ MCCs (Figure 2). Loss of aggrecan was associated with osteoarthritic changes that were noted in $\mathrm{H} \& \mathrm{E}$ stainings (Figure 3A, 24 weeks), which included tissue clefting (triangle). In support of this concept, Modified 
A

A WT $\begin{aligned} & \mathrm{Bgn}^{-10} \\ & \mathrm{Fmod}^{-1}\end{aligned} \quad$ WT $\begin{aligned} & \mathrm{Bgn}^{-1 / 0} \\ & \mathrm{Fmod}^{-/-}\end{aligned}$WT $\begin{aligned} & \mathrm{Bgn}^{-10} \\ & \mathrm{Fmod}^{-/}\end{aligned}$

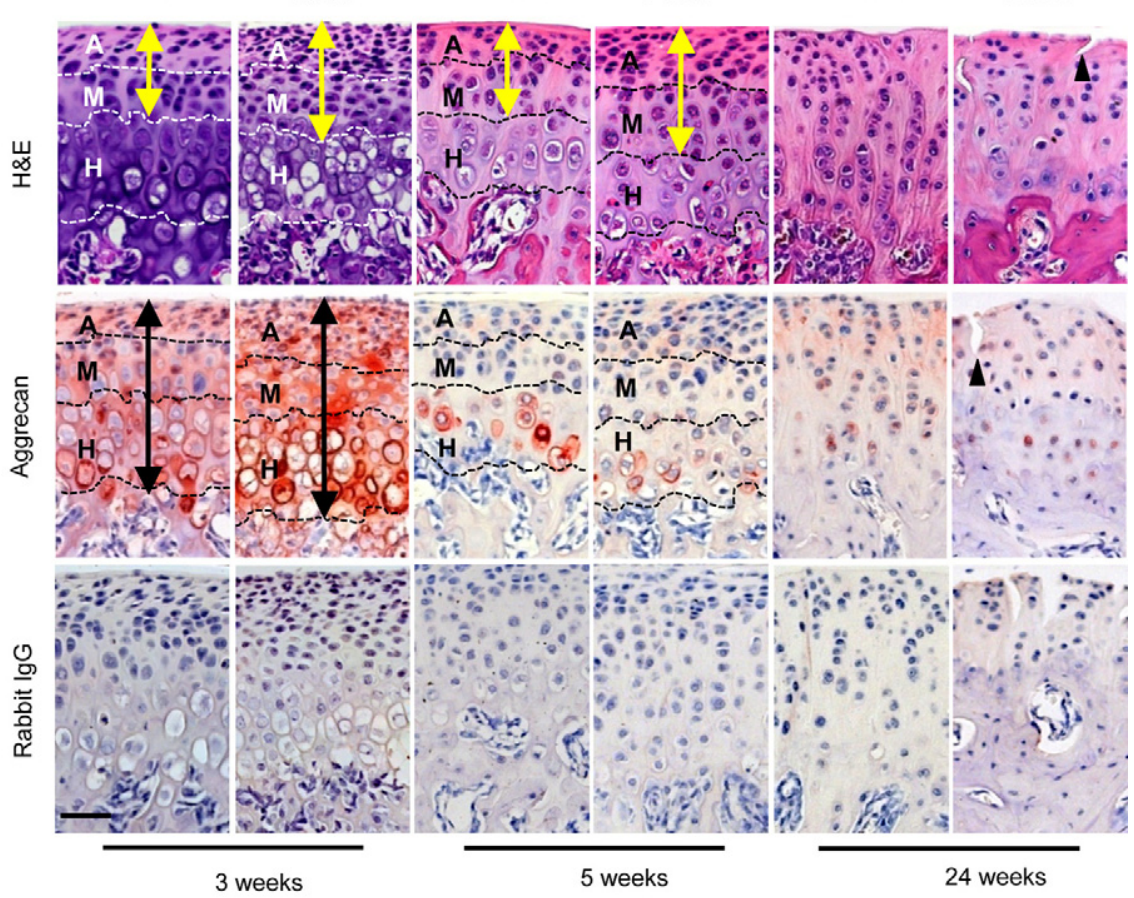

Figure 3. Accelerated degeneration of mandibular condylar cartilage and loss of aggrecan expression with aging in the absence of Bgn and Fmod. A: Comparable sections from wild-type (WT) and $\mathrm{Bgn}^{-/ 0} \mathrm{Fmod}^{-1-}$ condylar cartilages at 3,5 , and 24 weeks of age were stained with H\&E and aggrecan expression was assessed by immunohistochemistry. Rabbit IgG was used under the same conditions as negative controls Dashed lines divide the condyle into articular zone (A), mature zone (M), and hypertrophic zone $(\mathrm{H})$. Yellow arrows indicate extent of articular/mature zones and black arrows indicate extent of aggrecan immunostaining. Black triangle indicates tissue clefting. Scale bar = $50 \mu \mathrm{m}$. B: Semiquantitative modified Mankin score was used to assess histological changes in the wild-type and $\mathrm{Bgn}^{-10} \mathrm{Fmod}^{-1-}$ condylar cartilages on aging. Values are mean score \pm SD of four mice. ${ }^{*} P<0.003 \mathrm{Bgn}^{-/ 0} \mathrm{Fmod}^{-/-}$versus wild-type. C: The Blyscan glycosaminoglycan assay was used to determine the GAG content in wild-type and $\mathrm{Bgn}^{-/ 0} \mathrm{Fmod}^{-1-}$ condylar cartilages at 12 and 32 weeks. The GAG content was normalized to the mass of the sample. Values are mean score \pm SEM of 6 mice. ${ }^{*} P<0.008 \mathrm{Bgn}^{-/ 0}$ Fmod $^{-1-}$ versus wild-type.

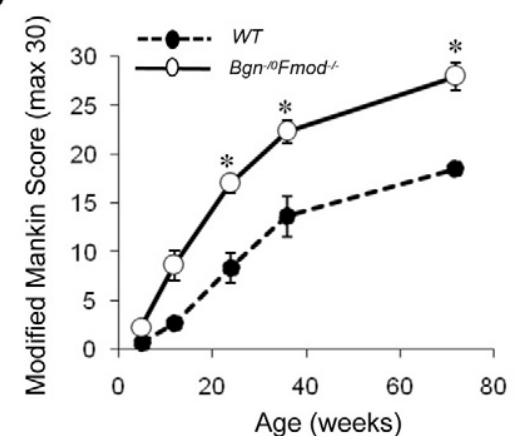

C

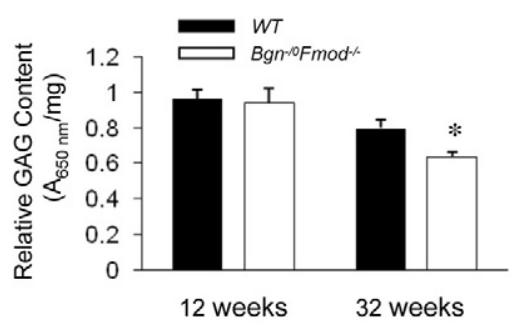

Mankin scores showed significant degenerative changes on aging in the $\mathrm{Bgn}^{-10} \mathrm{Fmod}^{-1-}$ mice (Figure 3B). These degenerative changes were also accompanied by an increase in the content of Comp (supplemental Figure S3 at $h$ ttp://ajp.amjpathol.org), an indicator of cartilage degeneration. ${ }^{36,37}$ Therefore, despite the fact that $\mathrm{Bgn}^{-10}$ Fmod $^{-1-}$ MCCs were able to produce more aggrecan compared with wild-type MCCs, the content of aggrecan in the $\mathrm{Bgn}^{-10} \mathrm{Fmod}^{-1-}$ mandibular condylar cartilage decreased faster than in the wild-type mandibular condylar cartilage. We speculated that this could be attributable to increased ECM degradation in $\mathrm{Bgn}^{-10} \mathrm{Fmod}^{-1-}$ mice.

We hypothesized localized aggrecan loss would alter total GAG content in the $\mathrm{Bgn}^{-10} \mathrm{Fmod}^{-1-}$ condylar cartilage. Therefore, we used a modified dimethylmethylene blue assay to determine total GAG content at 12 and 32 weeks (Figure $3 \mathrm{C}$ ). No significant differences in total GAG content were noted at 12 weeks. However, at 32 weeks there was a significant decrease in total GAG content in the $\mathrm{Bgn}^{-10} \mathrm{Fmod}^{-1-}$ condylar cartilage compared with the wild-type condylar cartilage. We suspect that at the early stages of TMJ OA in $\mathrm{Bgn}^{-10} \mathrm{Fmod}^{-1-}$ mice the specific changes in aggrecan localization are regional and best determined using immunohistochemistry. On aging, this specific aggrecan loss accumulates and ultimately causes a net decrease in the total GAG content that could only be detected during late-stage TMJ OA.

\section{TGF- $\beta 1$ Induces Chondrogenesis and Degeneration of Mandibular Condylar Cartilage}

To understand the underlying mechanisms that cause increased chondrogenesis and degeneration of mandibular condylar cartilage in the absence of Bgn and Fmod, we focused on the growth factors and cytokines that are regulated by SLRPs. It has been shown that SLRPs bind to members of transforming growth factor superfamily ${ }^{23}$ and regulate their effects on bone marrow stromal cells, osteoblasts, and tendon stem/precursor cells by sequestering the growth factors within the ECM. ${ }^{24}$ TGF- $\beta 1$ is one 
member of this family that is a potent regulator of chondrogenesis and plays a vital role in during OA pathology. ${ }^{25-27,38,39}$ We therefore determined the effects of TGF- $\beta 1$ on the proliferation, differentiation, and function of MCCs. We found that TGF- $\beta 1$ increased proliferation of MCCs (Figure 4A). Furthermore, TGF- $\beta 1$ induced the expression of transcription factors, sox5, sox6, and sox9, that are critical for chondrogenesis, as well as the ECM genes, agg, col2a1 and col10a1, that are important for cartilage formation and maintenance (Figure 4B). These data indicated that TGF- $\beta 1$ is a positive regulator of chon-

A
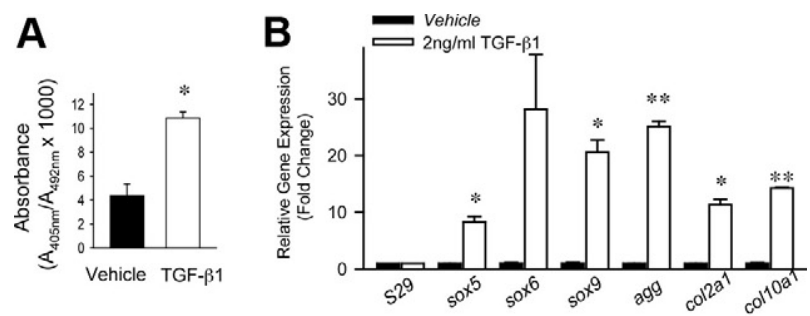

C
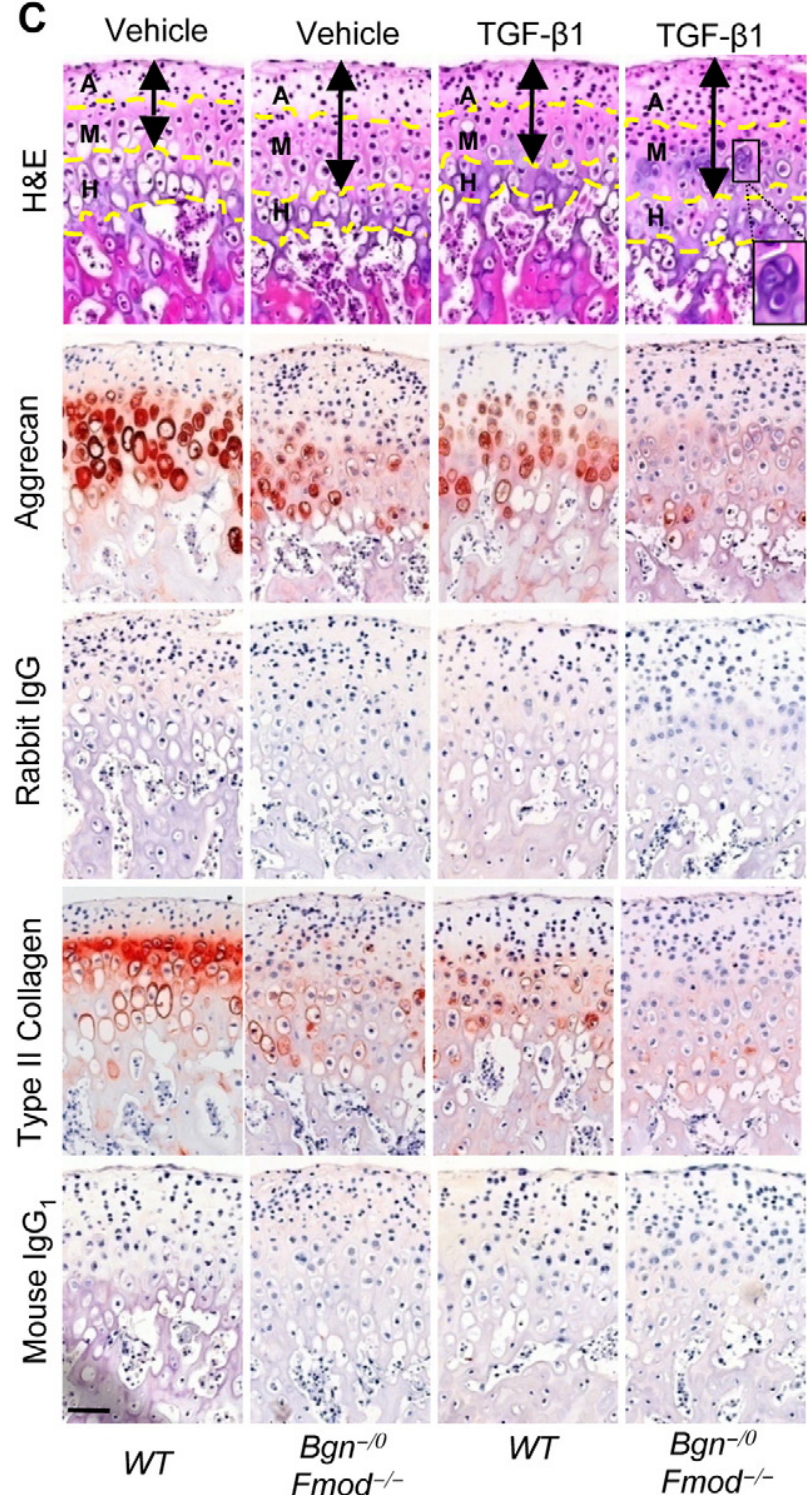

drogenesis in MCCs. Therefore the increase in proliferation and differentiation of MCCs initially observed in the $\mathrm{Bgn}^{-10} \mathrm{Fmod}^{-1-}$ mice may be attributable to overactivated TGF- $\beta 1$ signaling.

To test whether TGF- $\beta 1$ plays a role in the degeneration of mandibular condylar cartilage, we examined the effect of TGF- $\beta 1$ on aggrecan content using mandibular condyle explant cultures. Explants from 5-week-old mice were used because this was the age we first observed loss of aggrecan content. H\&E stainings and quantitative histological evaluation revealed that $\mathrm{Bgn}^{-10} \mathrm{Fmod}^{-1-}$ explants displayed a significant increase in the number of cells and area of the articular and mature zones, whereas no significant changes were noted within the hypertrophic zone (Figure 4C, black arrows, supplemental Table S2 at http://ajp.amjpathol.org). On TGF- $\beta 1$ treatment, wildtype explants also had a similar phenotype. However, the phenotype in $\mathrm{Bgn}^{-10} \mathrm{Fmod}^{-1-}$ explants was more severe with a significant increase in the formation of chondrocyte clusters and articular zone area (Figure 4C, supplemental Table S2 at http://ajp.amjpathol.org). Increased cellularity could be attributable to increased proliferation of MCCs, which led to the expansion of the articular zone. TGF- $\beta 1$ decreased aggrecan content in wild-type mandibular condyle explants and nearly eliminated aggrecan content in $\mathrm{Bgn}^{-10} \mathrm{Fmod}^{-1-}$ condyle explants (Figure $4 \mathrm{C}$ ). Similar changes were observed for type II collagen content, where TGF- $\beta 1$ decreased type II collagen in wildtype condyle explants and eliminated type II collagen content in $\mathrm{Bgn}^{-10} \mathrm{Fmod}^{-1-}$ mandibular condyle explants. Quantitative evaluation of immunohistochemistry confirmed that the area of aggrecan and type II collagen immunoreactivity in all samples was significantly lower when treated with TGF- $\beta 1$ (supplemental Table S2 at http://ajp.amjpathol.org). Overall, wild-type mandibular condyle explants treated with TGF- $\beta 1$ mimicked the phenotype that was found in $\mathrm{Bgn}^{-10} \mathrm{Fmod}^{-1-}$ mandibular condyle explants. TGF- $\beta 1$ treatment caused the phenotype to be more severe in $\mathrm{Bgn}^{-10} \mathrm{Fmod}^{-1-}$ mandibular condyle explants (Figure $4 C$ ). These data suggested that overactive TGF- $\beta 1$ signals might be responsible for the hypercellularity and the loss of aggrecan and type ॥ collagen content in the absence of Bgn and Fmod.

\footnotetext{
Figure 4. TGF- $\beta 1$ accelerates both formation and degeneration of mandibular condylar cartilages in the absence of Bgn and Fmod. A: TGF- $\beta 1$ induces proliferation of MCCs. BrdU ELISA was used to measure proliferation of MCCs treated with vehicle or TGF- $\beta 1$. Data are mean \pm SEM of 6 wells. ${ }^{*} P<$ 0.005 vehicle versus TGF- $\beta 1$. B: TGF- $\beta 1$ induces the expression of chondrogenic-related genes in the MCCs. Quantitative real-time RT-PCR analysis compared the expression levels of chondrogenic-related genes using total RNA isolated from MCCs treated with vehicle or TGF- $\beta 1$. Gene expression was normalized to the housekeeping gene S29. The expression of genes in MCCs treated with vehicle was relative to that in MCCs treated with TGF- $\beta 1$. Data are mean \pm SEM of 2 experiments. ${ }^{*} P<0.02,{ }^{*}{ }^{* *} P<0.002$ vehicle versus TGF- $\beta 1$. C: TGF- $\beta 1$ accelerates loss of aggrecan content in mandibular condyle explants. Whole mandibles were isolated from wild-type and $B g n^{-/ 0}$ Fmod $^{-1}$ mice and explants were cultured for 48 hours with vehicle or 2 $\mathrm{ng} / \mathrm{ml}$ TGF- $\beta 1$. Comparable histological sections from explants were stained with H\&E. Aggrecan and type II collagen expression was examined by immunohistochemistry. Rabbit IgG and mouse $\operatorname{IgG}_{1}$ were used under the same conditions as negative controls, respectively. Dashed yellow lines divide the condyle into articular zone (A), mature zone (M) and hypertrophic zone (H). Black double-ended arrows indicate extent of articular and mature zones. Black square indicates chondrocyte cluster. Scale bar $=50 \mu \mathrm{m}$.
} 
A

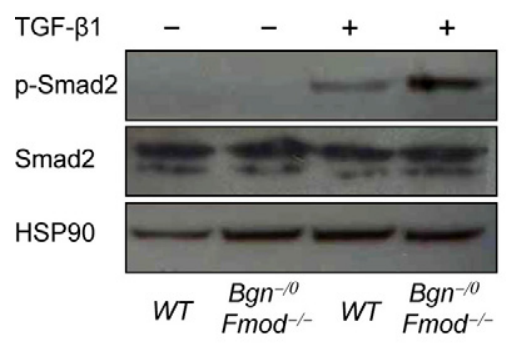

C

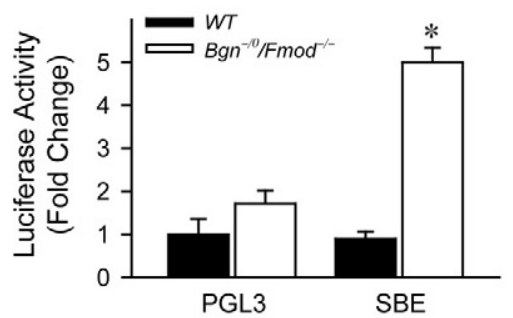

E

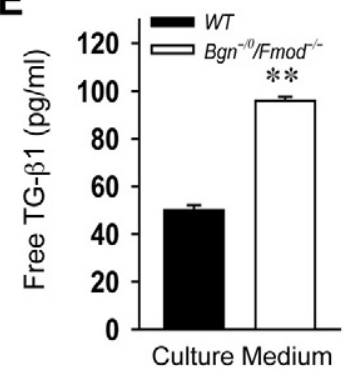

B

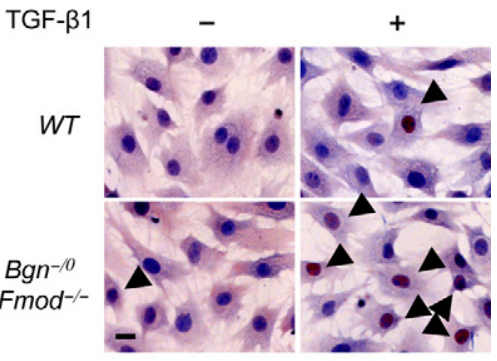

D

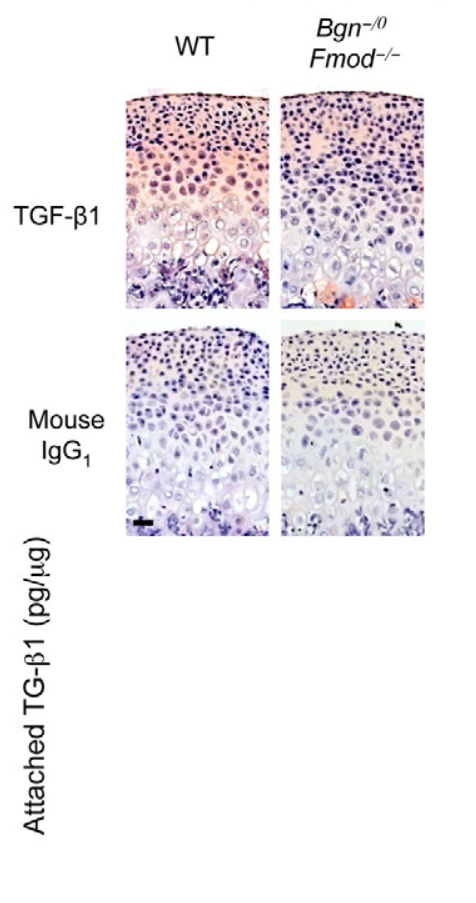

Figure 5. Decreased TGF- $\beta 1$ sequestration leads to overactivation of TGF- $\beta 1$ signaling in the absence of Bgn and Fmod. A: Increased phosphorylation of Smad2 in MCCs in the absence of Bgn and Fmod. Western blot analysis was used to determine Smad2 and phosphorylated Smad2 (p-Smad2) levels in wild-type (WT) and $\mathrm{Bgn}^{-/ 0} \mathrm{Fmod}^{-1-}$ MCCs treated with vehicle or $2 \mathrm{ng} / \mathrm{ml} \mathrm{TGF-} \beta 1$. HSP90 was used as protein loading control. B: Increased Smad4 nuclear translocation in the absence of Bgn and Fmod. Immunocytochemistry was used to examine the nuclear localization of Smad4 (arrows) in wild type and $\mathrm{Bgn}^{-/ 0} \mathrm{Fmod}^{-/-}$MCCs treated with vehicle or TGF- $\beta 1$. Scale bar $=20 \mu \mathrm{m}$. C: Increased TGF- $\beta 1$ responsive transcriptional activity in the absence of Bgn and Fmod. TGF$\beta 1$-induced transcriptional activity was determined by transfecting wild-type and $\mathrm{Bgn}^{-}$ oFmod $^{\prime-}$ MCCs with a reporter plasmid expressing a TGF- $\beta$ responsive luciferase construct (SBE). pGL3 was used as control. Data are mean \pm SEM of two to three transfections. ${ }^{*} P<$ $0.006 \mathrm{Bgn}^{-/ 0} \mathrm{Fmod}^{-/-}$versus wild-type. D: Decreased sequestration of active TGF- $\beta 1$ in ECM of mandibular condylar cartilage in the absence of Bgn and Fmod. The expression of active TGF- $\beta 1$ was examined by immunohistochemistry using comparable histological sections from 3-week-old wild-type and $\mathrm{Bgn}^{-/ 0} \mathrm{Fmod}^{-1}$ mandibular condylar cartilages. Mouse $\mathrm{IgG}_{1}$ was used under the same conditions as a negative control. Scale bar $=50 \mu \mathrm{m}$. E: Decreased TGF- $\beta 1$ binding to ECM and cells in the absence of Bgn and Fmod. Confluent wild-type and $\mathrm{Bgn}^{-/ 0} \mathrm{Fmod}^{-/-}$MCCs were cultured with vehicle or $1 \mathrm{ng} / \mathrm{ml}$ TGF- $\beta 1$. The concentration of unbound TGF- $\beta 1$ in the culture media (left) and the levels of active TGF- $\beta 1$ bound to the cell layer (cell surface and ECM; right) were measured by ELISA. Data are mean \pm SEM of three to four wells. ${ }^{*} P<0.01,{ }^{* *} P<0.0001 \mathrm{Bgn}^{-}$ $\mathrm{oFmod}^{-1-}$ versus wild-type.

\section{TGF- $\beta 1$ Signal Transduction Is Overactivated in Mandibular Condylar Cartilage in the Absence of Bgn and Fmod}

To test whether TGF- $\beta 1$ signal transduction was overactivated, we examined the expression of molecules that are critical for TGF- $\beta 1$ signal transduction. TGF- $\beta 1$ binds to its receptors and signals specifically through phosphorylation of members of the Smad family, Smad2/3. Phosphorylated Smad2/3 form heterodimers with Smad4 and translocate to the nucleus and act as transcription factors regulating cell growth, differentiation, and function. The expression levels of Smad2 were unchanged in wild-type and $\mathrm{Bgn}^{-10} \mathrm{Fmod}^{-1-} \mathrm{MCC}$ in the presence and absence of TGF- $\beta 1$. However, on TGF- $\beta 1$ stimulation, the phosphorylation of Smad2 was much higher in $\mathrm{Bgn}^{-10}$ Fmod $^{-1-}$ MCCs than in wild-type MCCs (Figure 5A). Immunocytochemistry staining showed the number of MCCs with Smad4 nuclear localization was 2.1-fold higher in the $\mathrm{Bgn}^{-10} \mathrm{Fmod}^{-1-}$ MCCs than wild-type MCCs (Figure 5B, arrows). Furthermore, transcriptional activity of a TGF- $\beta 1$ responsive luciferase reporter construct (4X SBE) was higher in $\mathrm{Bgn}^{-10} \mathrm{Fmod}^{-1-}$ MCCs compared with wild-type MCCs (Figure 5C). These data all point to the conclusion that TGF- $\beta 1$ signaling is overactivated in the $\mathrm{Bgn}^{-10} \mathrm{Fmod}^{-1-}$ mandibular condylar cartilage and cells.

Both Bgn and Fmod bind to active TGF- $\beta 1$ to regulate its activity. ${ }^{23}$ We predicted that Bgn and Fmod regulate TGF- $\beta 1$ activity by binding and sequestering it within the ECM. In the absence of Bgn and Fmod, active TGF- $\beta 1$ could not be trapped or sequestered in the ECM. Immunohistochemistry showed that TGF- $\beta 1$ immunoreactivity was less extensive in the ECM of the $\mathrm{Bgn}^{-10} \mathrm{Fmod}^{-1-}$ condylar cartilages compared with wild-type tissues (Figure 5D). To further confirm this, we performed an in vitro "sequestration" experiment by adding 2 ng/ml TGF- $\beta 1$ to confluent MCCs cultures and measuring the concentration of TGF- $\beta 1$ in the media versus TGF- $\beta 1$ binding to wild-type and $\mathrm{Bgn}^{-10} \mathrm{Fmod}^{-1-}$ cell layers (matrices) as previously described. ${ }^{24}$ The amount of unbound TGF- $\beta 1$ was significantly higher in the $\mathrm{Bgn}^{-10} \mathrm{Fmod}^{-1-}$ culture medium (Figure $5 E$ left), whereas the amount of TGF- $\beta 1$ detected in the cell layer was lower in the $\mathrm{Bgn}^{-10} \mathrm{Fmod}^{-1-}$ MCCs (Figure 5E, right). These data suggested that active TGF- $\beta 1$ sequestration was decreased in the matrices that are devoid of Bgn and Fmod. Therefore, increased free active TGF- $\beta 1$ in the $\mathrm{Bgn}^{-10} \mathrm{Fmod}^{-1-}$ condylar cartilage ECM resulted in increased TGF- $\beta 1$ signal transduction in MCCs. 
A
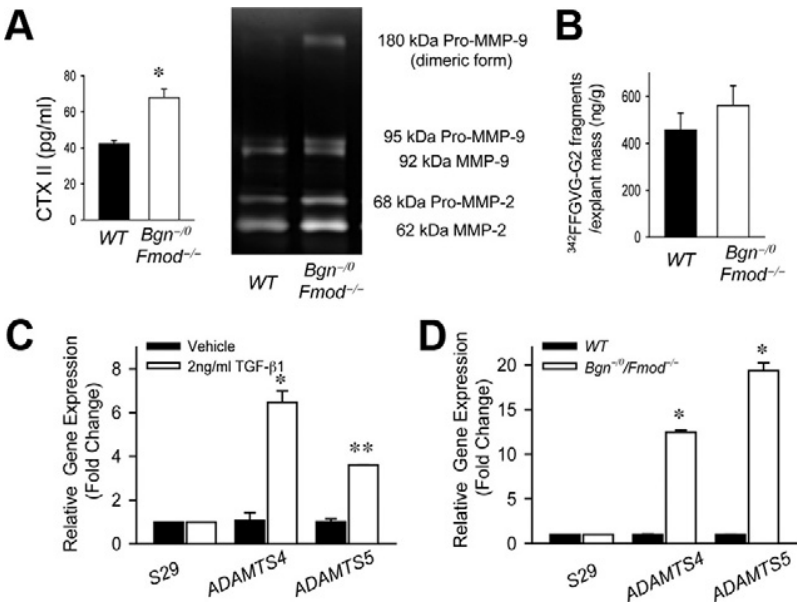

Figure 6. MMP and aggrecanase expression and activity are increased in the absence of Bgn and Fmod. A: Increased release of CTX II and MMP activity in the absence of Bgn and Fmod. Type II collagen degradation was determined using CTX-II ELISA, which measured the release of the MMP-derived type II collagen fragment CTX-II in culture medium of wild-type (WT) and $\mathrm{Bgn}^{-/ 0} \mathrm{Fmod}^{-1-}$ explants (left). Gelatin zymography was used to determine the MMP activity in the culture medium of wild-type and $\mathrm{Bgn}^{-/ 0} \mathrm{Fmod}^{-1-}$ explants (right). Data are mean \pm SEM of 12 explants. ${ }^{*} P<0.008 \mathrm{Bgn}^{-/ 0}$ Fmod $^{-1}$ versus wild-type. B: MMP mediated aggrecan degradation was unaffected in the absence of Bgn and Fmod. The release of the MMP mediated aggrecan fragment ${ }^{342}$ FFGVG-G2 in the culture media of wild-type and $\mathrm{Bgn}^{-/ 0} \mathrm{Fmod}^{-1-}$ explants was measured by ELISA. Data are mean \pm SEM of nine to twelve explants. C: TGF- $\beta 1$ up-regulates the expression of ADAMTS4 and ADAMTS5 in MCCs. Quantitative real-time RT-PCR analysis was used to examine the expression of ADAMTS4 and ADAMTS5 using total RNA isolated from MCCs treated with vehicle or TGF- $\beta 1$. Gene expression was normalized to the housekeeping gene S29. The gene expression levels in cultures with TGF- $\beta 1$ were relative to the cultures with vehicle. Data are mean \pm SEM of 2 experiments. ${ }^{*} P<0.02,{ }^{* *} P<0.003$ TGF- $\beta 1$ versus vehicle D: Increased expression of ADAMTS4 and ADAMTS5 in the absence of Bgn and Fmod. Quantitative real-time RT-PCR analysis was used to examine the expression of ADAMTS4 and ADAMTS5 using total RNA isolated from wild type and $\mathrm{Bgn}^{-/ 0} \mathrm{Fmod}^{-1-}$ cultured MCCs. Gene expression was normalized to the housekeeping gene S29. The gene expression levels in $B g n^{-/ 0}$ Fmod $^{-1}$ MCCs were relative to wild-type MCCs. Data are mean \pm SEM of 3 experiments. ${ }^{*} \mathrm{P}<0.0001 \mathrm{Bgn}^{-/ 0} \mathrm{Fmod}^{-1-}$ versus wild-type MCCs.

\section{MMP and Aggrecanase Expression and Activity Are Increased in the Mandibular Condylar Cartilage in the Absence of Bgn and Fmod}

TGF- $\beta 1$ stimulates degradation of proteoglycans and ultimately degeneration of cartilage by increasing the production of MMP and aggrecanases. ${ }^{26}$ Therefore, we hypothesized that overactivated TGF- $\beta 1$ signaling in the absence of Bgn and Fmod increased the degradation of ECM components by increasing the activity of MMPs and aggrecanases. Type II collagen is degraded mainly by MMPs. ${ }^{40}$ We found that the release of type II collagen C-telopeptide degradation products (CTX-II) was increased in the medium of $\mathrm{Bgn}^{-10} \mathrm{Fmod}^{-1-}$ explant cultures compared with wild-type explant cultures (Figure $6 \mathrm{~A}$ ). To test whether the increased type II collagen breakdown was mediated by MMPs, we used gelatinase zymography to measure the expression and activity of MMP-2 and MMP-9. As expected, the expression and activity of both MMP-2 and MMP-9 were higher in the medium of $\mathrm{Bgn}^{-10} \mathrm{Fmod}^{-1-}$ explants cultures compared with wild-type explants cultures (Figure 6A). The most abundant proteoglycan in articular cartilage is aggrecan, which can also be cleaved by MMPs at the interglobular domain. ${ }^{14,41}$ MMP-mediated aggrecan degradation results in the specific generation of aggrecan neo-epitopes corresponding to the FFGVG sequences at the $\mathrm{N}$ terminus. ${ }^{30}$ To determine whether overactive TGF- $\beta 1$ signaling affects MMP-mediated aggrecan degradation, we measured the amount of aggrecan neo-epitopes released in the culture medium of the explants cultures using an ELISA based on a monoclonal antibody targeting FFGVG sequences. ${ }^{42}$ The release of this aggrecan fragment in the $\mathrm{Bgn}^{-10} \mathrm{Fmod}^{-1-}$ explant culture medium was not significantly different from wild-type explant culture medium (Figure 6B). Therefore, in the absence of Bgn and Fmod, overactive TGF- $\beta 1$ signaling accelerated type II collagen, but not aggrecan degradation by increasing MMP expression and activity.

Most aggrecan is cleaved by aggrecanases, also called a disintegrin and metalloproteases with thrombospondin motifs (ADAMTS). ${ }^{43}$ ADAMTS4 and ADAMTS5 are the major aggrecanases and play a pivotal role in $\mathrm{OA}$ of other joints. ${ }^{44,45}$ Previous studies showed that TGF- $\beta 1$ mediates the expression of ADAMTS in human chondrocytes. ${ }^{26}$ Therefore, we explored whether TGF- $\beta 1$ regulates the expression of ADAMTS4 and ADMATS5 in MCCs. Real time RT-PCR analysis revealed that TGF- $\beta 1$ up-regulated both ADAMTS4 and ADAMTS5 in MCCs (Figure 6C). Furthermore, the expression of ADAMTS4 and ADAMTS5 was up-regulated in $\mathrm{Bgn}^{-10} \mathrm{Fmod}^{-1-}$ MCCs in comparison with wild-type MCCs (Figure 6D), which may be attributable to overactivated TGF- $\beta 1$ signaling. Thus, overactive TGF- $\beta 1$ signaling in the absence of Bgn and Fmod likely accelerated aggrecan degradation through the up-regulation of ADAMTS4 and ADAMTS5.

Taken together, ECM controls the formation and degradation of TMJ condylar cartilage by regulating availability of active TGF- $\beta 1$. Overactive TGF- $\beta 1$ signaling in the absence of Bgn and Fmod increases turnover in mandibular condylar cartilage by increasing both ECM protein synthesis and degradation. At an early age, ECM protein synthesis plays a dominant role, where we find increased content of type II collagen and aggrecan in the absence of Bgn and Fmod. With aging, ECM protein degradation becomes dominant and subsequently causes cartilage degeneration. In the absence of Bgn and Fmod, because of high ECM turnover, the switch to mandibular condylar cartilage degeneration dominance over mandibular condylar cartilage formation occurs much earlier, which leads to the early onset of TMJ OA.

\section{Discussion}

The chondrocyte is critical for cartilage tissue maintenance because it coordinates ECM synthesis, assembly, and degradation. To understand basic cellular mechanisms underlying TMJ OA, we harvested primary MCCs. Because the mandibular condylar cartilage is distinct from knee hyaline articular cartilage, ${ }^{3-8}$ we compared MCCs with HACs isolated from the knee joint. Our mRNA and protein profiling revealed that the two cell populations share overlaping gene/protein expression patterns. 
However, like the tissues they are derived from, the two cell types are heterogeneous and distinct from each other in many ways. Our studies revealed that in comparison with HACs, MCCs had more precursor cells that expressed type I collagen, and fewer mature chondrocytes that expressed type II collagen and aggrecan. Our findings are consistent with other studies demonstrating isolated MCCs contained multiple differentiated cell types, which emulated the different cellular maturation zones within the in vivo mandibular condyle..$^{8,46}$

Although chondrocytes harvested from knee hyaline articular cartilage also demonstrate heterogeneity, ${ }^{33}$ the expression of type I collagen in cell monolayers is indicative of chondrocyte dedifferentiation to an earlier fibroblastic stage. ${ }^{47,48}$ Consequently, three-dimensional systems are required to maintain type II collagen expression and mature chondrocyte phenotype. ${ }^{48}$ Consistent with this concept, our data revealed that HACs expressed type I collagen in monolayer cultures, but not in differentiated pellet cultures. On the other hand, when induced to undergo chondrogenesis in pellet cultures, MCCs maintained a fibrocartilage-like phenotype and simultaneously expressed both type I collagen and type II collagen. This suggests that MCCs may contain a unique population of precursor cells that are most likely derived from the articular zone, which is present in the TMJ but not in the knee. ${ }^{8}$ Therefore, the specialized nature of MCCs underscores the importance of using them specifically to study the TMJ.

The ECM is a potent indicator of normal chondrocyte function and may, in turn, help mediate chondrocyte function during tissue maintenance. ${ }^{13}$ In support of this idea, changes in the distribution, expression, and production of SLRPs in osteoarthritic tissue implicate that SLRP family members may function to maintain normal chondrocyte activity and cartilage tissue integrity. ${ }^{17,49,50}$ Specifically, elevated levels of discrete fragmented forms of Bgn, Fmod, and other SLRPs were discovered in patients with degenerating articular cartilage, ${ }^{50}$ and generalized proteoglycan loss was apparent in late-stage osteoarthritic cartilage lesions. ${ }^{49}$ Simultaneously, as an attempt to repair damaged ECM, chondrocytes increased the production of the SLRPs. ${ }^{14,49,50}$ These data indicate alterations in the distribution and production of SLRPs could lead to the development of joint degenerative diseases. Consequently, to study how ECM proteins regulate mandibular condylar cartilage formation and maintenance in the TMJ, we used a mouse model of TMJ OA that is deficient in two SLRPs, Bgn and Fmod. ${ }^{18}$

In this study we show that the absence of ECM proteoglycans Bgn and Fmod prevented TGF- $\beta 1$ sequestration within the ECM, leading to overactive TGF- $\beta 1 /$ Smad2/3 signaling. TGF- $\beta 1$ and ECM interactions are critical for modulating TGF- $\beta 1$ activity and function. The dysregulation of TGF- $\beta 1$ caused by defects in ECM components has been implicated in a variety of diseases, including muscular disorders. ${ }^{51}$ Additionally, in a mouse model of Marfan syndrome, deficiency of one ECM protein fibrillin- 1 is associated with dysregulated TGF- $\beta 1$ activation and increased signaling in the lung and heart, causing pulmonary emphysema and mitral valve pro- lapsed, respectively. ${ }^{52,53}$ More specifically, SLRP family members have been shown to modify TGF- $\beta 1$ bioavailability and/or function by binding to and sequestering TGF- $\beta 1$ within the ECM. ${ }^{23}$ Alterations in SLRP content can lead to dysregulated TGF- $\beta 1$ activity and subsequent disease pathologies through mechanisms that are both SLRP- and tissue-specific. ${ }^{17,24,54}$ The most notable cartilage study involves asporin, ${ }^{55}$ a Class I SLRP that is closely related to biglycan and decorin. ${ }^{55}$ The study revealed the association of a polymorphism in the aspartic acid repeat regions (D14 allele) in Asp in a population with knee and hip OA. ${ }^{17}$ The addition of the D14 enhanced the Asp binding affinity to TGF- $\beta 1$ and inhibited chondrogenesis. Taken together, these data indicate that SLRP family members play dominant roles in the tight regulation of TGF- $\beta 1$ bio-availability and subsequent activity. Our data sheds new light on the complexity of this functional relationship in a novel tissue, the TMJ.

Several lines of evidence demonstrate that suppression of TGF- $\beta 1$ signals often corresponds with an OA-like pathology. For example, reduced TGF- $\beta 1$ signaling and absence of TGF- $\beta 1$ responsiveness have been associated with spontaneous and surgical models of OA. ${ }^{56,57}$ Moreover, the total inhibition of TGF- $\beta 1 / \mathrm{Smad}$ signaling by genetic means, such as by the depletion of Smad3 or by overexpressing a dominant-negative TGF- $\beta$ type ॥ receptor, resulted in the overt promotion of terminal chondrocyte differentiation and an OA-like phenotype. ${ }^{58,59}$ These data suggest that TGF- $\beta 1 / \mathrm{Smad}$ signals maintain articular cartilage tissue by inhibiting chondrocyte terminal differentiation. Consequently, embryonic metatarsal explant cultures treated with large doses of TGF- $\beta 1$ (10 $\mathrm{ng} / \mathrm{ml}$ ) resulted in a significant decrease in the length of the hypertrophic zone. ${ }^{60}$ Our study showed that mandibular explants cultures treated with small doses of TGF- $\beta 1$ $(2 \mathrm{ng} / \mathrm{ml})$ resulted in no significant changes in the hypertrophic zone area. Furthermore, in the absence of Bgn and Fmod the small increases in TGF- $\beta 1 / \mathrm{Smad} 3$ signals over an extended period of time also resulted in no apparent changes in the hypertrophic zone area. Taken together, these data indicate that TGF- $\beta 1$-mediated inhibition of chondrocyte terminal differentiation may be tissue- and/or dose-dependent.

Given that suppression of TGF- $\beta 1$ signals often corresponds with $O A$, it is not surprising that exogenous TGF- $\beta 1$ has been tested as a potential therapeutic to promote ECM synthesis or repair in both the knee and TMJ of mice. ${ }^{21,27,61}$ However, whereas intra-articular injections of TGF- $\beta 1$ into mouse knee joints initially stimulated proteoglycan synthesis, prolonged TGF- $\beta 1$ treatment also facilitated the development of key histopathological features of OA, such as proteoglycan degradation, cellular disorganization, and osteophyte formation. ${ }^{38}$ Consequently, brief TGF- $\beta 1$ exposure may be beneficial, whereas longer TGF- $\beta 1$ exposure may be damaging. Remarkably, these findings and concept are similar to our results. We show that, in the absence of Bgn and Fmod, overactive TGF- $\beta 1$ signals initially induced chondrogenesis and ECM production in younger mice. On aging, prolonged exposure to overactive TGF- $\beta 1$ signals ultimately induced ECM degradation and TMJ OA in 
our model. Consistent with this concept, TGF- $\beta 1$ expression was elevated in human OA chondrocytes ${ }^{39,62}$ and also in the synovial joint fluid of a trauma-induced OA model in rabbits. ${ }^{63}$ Therefore, SLRPs may function to regulate the beneficial versus harmful effects of TGF- $\beta 1$ signals. Our data identified Bgn and Fmod as vital for the precise regulation of TGF- $\beta 1$ activity in maintaining the balance of ECM turnover in TMJ tissue, where even small changes in TGF- $\beta 1$ bioavailability had profound effects on TMJ tissue integrity over time.

We further demonstrated that TGF- $\beta 1$ mediated mandibular condylar cartilage degeneration and loss of aggrecan content by potentially increasing the production of aggrecanases. In support of this idea, the expression of ADAMTS5 was up-regulated in articular disks of patients with TMJ OA. ${ }^{64}$ Specifically, we showed that the MMP-derived aggrecan FFGVG neoepitope was not significantly different in our model, whereas both ADAMTS4 and ADAMTS5 mRNA levels were higher in $\mathrm{Bgn}^{-10}$ $\mathrm{Fmod}^{-1-} \mathrm{MCC}$. This suggests that aggrecanases primarily mediated aggrecan degradation and not MMPs. Similarly, in vitro studies using human osteoarthritic chondrocytes have shown that aggrecan molecules may be cleaved by either MMPs or aggrecanase within the interglobular domain, but not by both simultaneously. ${ }^{41}$ Furthermore, our data demonstrated that TGF- $\beta 1$ induced the expression of ADAMTS4 and ADAMTS5 in MCCs and is consistent with findings that showed TGF- $\beta 1$ strongly increased aggrecanase mRNA levels in chondrocytes from normal and osteoarthritic cartilage. ${ }^{26}$

Overall, our studies demonstrated that the absence of ECM proteins Bgn and Fmod disrupted the balance between ECM formation and degradation, and lead to the development TMJ OA. Although our study focused on the growth factor TGF- $\beta 1$ exclusively, future studies may be implemented that call attention to other cytokines and growth factors potentially involved, such as IL-1 $\beta^{65}$ or Wnt proteins. ${ }^{66}$ Additionally, because our study showed that MCCs and HACs were phenotypically distinct, it would be interesting to compare the mechanisms regulating $\mathrm{Bgn}^{-10} \mathrm{Fmod}^{-1-} \mathrm{MCCs}$ to $\mathrm{Bgn}^{-10} \mathrm{Fmod}^{-1-} \mathrm{HACs}$. Although both the TMJ and knee degenerate in $\mathrm{Bgn}^{-10}$ $\mathrm{Fmod}^{-1-}$ mice, it is likely that the pathological processes are different given the knee phenotype was more severe and evolved more rapidly. ${ }^{18,19}$ The degenerative process in the TMJ is prolonged and affords the advantage of studying cellular responses to the absence of Bgn and Fmod, which helps define the exact role Bgn and Fmod play in mediating those responses. Nonetheless, we present here for the first time a comprehensive study identifying Bgn and Fmod as novel players in regulating chondrogenesis and ECM turnover during TMJ OA pathology.

\section{Acknowledgment}

We are grateful to the technical assistance of David Walker (NIDCR).

\section{References}

1. Scrivani SJ, Keith DA, Kaban LB: Temporomandibular disorders. N Engl J Med 2008, 359:2693-2705

2. Zarb GA, Carlsson GE: Temporomandibular disorders: osteoarthritis J Orofac Pain 1999, 13:295-306

3. Bosshardt-Luehrs CP, Luder HU: Cartilage matrix production and chondrocyte enlargement as contributors to mandibular condylar growth in monkeys (Macaca fascicularis). Am J Orthod Dentofacial Orthop 1991, 100:362-369

4. Meikle MC: Remodeling the dentofacial skeleton: the biological basis of orthodontics and dentofacial orthopedics. J Dent Res 2007, 86:12-24

5. Almarza AJ, Athanasiou KA: Design characteristics for the tissue engineering of cartilaginous tissues. Ann Biomed Eng 2004, 32:2-17

6. Shen G, Rabie AB, Zhao ZH, Kaluarachchi K: Forward deviation of the mandibular condyle enhances endochondral ossification of condylar cartilage indicated by increased expression of type $X$ collagen. Arch Oral Biol 2006, 51:315-324

7. Shen G, Darendeliler MA: The adaptive remodeling of condylar cartilage - a transition from chondrogenesis to osteogenesis. J Dent Res 2005, 84:691-699

8. Delatte M, Von den Hoff JW, van Rheden RE, Kuijpers-Jagtman AM: Primary and secondary cartilages of the neonatal rat: the femoral head and the mandibular condyle. Eur J Oral Sci 2004, 112:156-162

9. Suda N, Shibata S, Yamazaki K, Kuroda T, Senior PV, Beck F, Hammond VE: Parathyroid hormone-related protein regulates proliferation of condylar hypertrophic chondrocytes. J Bone Miner Res 1999, 14:1838-1847

10. Watahiki J, Yamaguchi T, Enomoto A, Irie T, Yoshie K, Tachikawa T, Maki K: Identification of differentially expressed genes in mandibular condylar and tibial growth cartilages using laser microdissection and fluorescent differential display: chondromodulin-I (ChM-1) and tenomodulin (TeM) are differentially expressed in mandibular condylar and other growth cartilages. Bone 2008, 42:1053-1060

11. Silbermann M, Reddi AH, Hand AR, Leapman RD, Von der Mark K, Franzen A: Further characterisation of the extracellular matrix in the mandibular condyle in neonatal mice. J Anat 1987, 151:169-188

12. Silbermann M, von der Mark K, Heinegard D: An immunohistochemical study of the distribution of matrical proteins in the mandibular condyle of neonatal mice. II Non-collagenous proteins. J Anat 1990, 170:23-31

13. Goldring MB, Goldring SR: Osteoarthritis. J Cell Physiol 2007, 213:626-634

14. Sandell LJ, Aigner T: Articular cartilage and changes in arthritis. An introduction: cell biology of osteoarthritis. Arthritis Res 2001, 3:107-113

15. Alexopoulos LG, Youn I, Bonaldo P, Guilak F: Developmental and osteoarthritic changes in Col6a1-knockout mice: biomechanics of type VI collagen in the cartilage pericellular matrix. Arthritis Rheum $2009,60: 771-779$

16. Hu K, Xu L, Cao L, Flahiff CM, Brussiau J, Ho K, Setton LA, Youn I Guilak F, Olsen BR, Li Y: Pathogenesis of osteoarthritis-like changes in the joints of mice deficient in type IX collagen. Arthritis Rheum 2006, 54:2891-2900

17. Kizawa H, Kou I, lida A, Sudo A, Miyamoto Y, Fukuda A, Mabuchi A, Kotani A, Kawakami A, Yamamoto S, Uchida A, Nakamura K, Notoya K, Nakamura Y, Ikegawa S: An aspartic acid repeat polymorphism in asporin inhibits chondrogenesis and increases susceptibility to osteoarthritis. Nat Genet 2005, 37:138-144

18. Wadhwa S, Embree MC, Kilts T, Young MF, Ameye LG: Accelerated osteoarthritis in the temporomandibular joint of biglycan/fibromodulin double-deficient mice. Osteoarthritis Cartilage 2005, 13:817-827

19. Ameye L, Aria D, Jepsen K, Oldberg A, Xu T, Young MF: Abnormal collagen fibrils in tendons of biglycan/fibromodulin-deficient mice lead to gait impairment, ectopic ossification, and osteoarthritis. FASEB J 2002, 16:673-680

20. Bauss O, Sadat-Khonsari R, Fenske C, Engelke W, Schwestka-Polly R: Temporomandibular joint dysfunction in Marfan syndrome. Oral Surg Oral Med Oral Pathol Oral Radiol Endod 2004, 97:592-598

21. Buckingham RB, Braun T, Harinstein DA, Oral K, Bauman D, Bartynski W. Killian PJ, Bidula LP: Temporomandibular joint dysfunction syndrome: a close association with systemic joint laxity (the hyper- 
mobile joint syndrome). Oral Surg Oral Med Oral Pathol 1991, 72:514-519

22. Bi Y, Ehirchiou D, Kilts TM, Inkson CA, Embree MC, Sonoyama W, Li L, Leet Al, Seo BM, Zhang L, Shi S, Young MF: Identification of tendon stem/progenitor cells and the role of the extracellular matrix in their niche. Nat Med 2007, 13:1219-1227

23. Hildebrand A, Romaris M, Rasmussen LM, Heinegard D, Twardzik DR, Border WA, Ruoslahti E: Interaction of the small interstitial proteoglycans biglycan, decorin and fibromodulin with transforming growth factor beta. Biochem J 1994, 302 (Pt 2):527-534

24. Bi Y, Stuelten CH, Kilts T, Wadhwa S, lozzo RV, Robey PG, Chen XD, Young MF: Extracellular matrix proteoglycans control the fate of bone marrow stromal cells. J Biol Chem 2005, 280:30481-30489

25. Blaney Davidson EN, van der Kraan PM, van den Berg WB: TGF-beta and osteoarthritis. Osteoarthritis Cartilage 2007, 15:597-604

26. Moulharat N, Lesur C, Thomas M, Rolland-Valognes G, Pastoureau P Anract $P$, De Ceuninck F, Sabatini M: Effects of transforming growth factor-beta on aggrecanase production and proteoglycan degradation by human chondrocytes in vitro. Osteoarthritis Cartilage 2004, 12:296-305

27. Grimaud E, Heymann D, Redini F: Recent advances in TGF-beta effects on chondrocyte metabolism. Potential therapeutic roles of TGF-beta in cartilage disorders. Cytokine Growth Factor Rev 2002, 13:241-257

28. Xu T, Bianco P, Fisher LW, Longenecker G, Smith E, Goldstein S, Bonadio J, Boskey A, Heegaard AM, Sommer B, Satomura K, Dominguez P, Zhao C, Kulkarni AB, Robey PG, Young MF: Targeted disruption of the biglycan gene leads to an osteoporosis-like phenotype in mice. Nat Genet 1998, 20:78-82

29. Svensson L, Aszodi A, Reinholt FP, Fassler R, Heinegard D, Oldberg A: Fibromodulin-null mice have abnormal collagen fibrils, tissue organization, and altered lumican deposition in tendon. J Biol Chem 1999, 274:9636-9647

30. Sumer EU, Sondergaard BC, Rousseau JC, Delmas PD, Fosang AJ, Karsdal MA, Christiansen C, Qvist P: MMP and non-MMP-mediated release of aggrecan and its fragments from articular cartilage: a comparative study of three different aggrecan and glycosaminoglycan assays. Osteoarthritis Cartilage 2007, 15:212-221

31. Fosang AJ, Last K, Gardiner P, Jackson DC, Brown L: Development of a cleavage-site-specific monoclonal antibody for detecting metalloproteinase-derived aggrecan fragments: detection of fragments in human synovial fluids. Biochem J 1995, 310 (Pt 1):337-343

32. Furman BD, Olson SA, Guilak F: The development of posttraumatic arthritis after articular fracture. J Orthop Trauma 2006, 20:719-725

33. Darling EM, Hu JC, Athanasiou KA: Zonal and topographical differences in articular cartilage gene expression. J Orthop Res 2004 22:1182-1187

34. Wadhwa S, Embree M, Ameye L, Young MF: Mice deficient in biglycan and fibromodulin as a model for temporomandibular joint osteoarthritis. Cells Tissues Organs 2005, 181:136-143

35. Rizkalla G, Reiner A, Bogoch E, Poole AR: Studies of the articular cartilage proteoglycan aggrecan in health and osteoarthritis. Evidence for molecular heterogeneity and extensive molecular changes in disease. J Clin Invest 1992, 90:2268-2277

36. Posey KL, Hecht JT: The role of cartilage oligomeric matrix protein (COMP) in skeletal disease. Curr Drug Targets 2008, 9:869-877

37. Williams FM, Spector TD: Biomarkers in osteoarthritis. Arthritis Res Ther 2008, 10:101

38. Bakker AC, van de Loo FA, van Beuningen HM, Sime P, van Lent PL, van der Kraan PM, Richards CD, van den Berg WB: Overexpression of active TGF-beta- 1 in the murine knee joint: evidence for synoviallayer-dependent chondro-osteophyte formation. Osteoarthritis Cartilage 2001, 9:128-136

39. Rollin R, Alvarez-Lafuente R, Marco F, Garcia-Asenjo JA, Jover JA, Rodriguez L, Lopez-Duran L, Fernandez-Gutierrez B: Abnormal transforming growth factor-beta expression in mesenchymal stem cells from patients with osteoarthritis. J Rheumatol 2008, 35:904-906

40. Kozaci LD, Buttle DJ, Hollander AP: Degradation of type II collagen, but not proteoglycan, correlates with matrix metalloproteinase activity in cartilage explant cultures. Arthritis Rheum 1997, 40:164-174

41. Fosang AJ, Last K, Maciewicz RA: Aggrecan is degraded by matrix metalloproteinases in human arthritis. Evidence that matrix metalloproteinase and aggrecanase activities can be independent. J Clin Invest 1996, 98:2292-2299
42. Karsdal MA, Madsen SH, Christiansen C, Henriksen K, Fosang AJ, Sondergaard BC: Cartilage degradation is fully reversible in the presence of aggrecanase but not matrix metalloproteinase activity. Arthritis Res Ther 2008, 10:R63

43. Fosang AJ, Little CB: Drug insight: aggrecanases as therapeutic targets for osteoarthritis. Nat Clin Pract Rheumatol 2008, 4:420-427

44. Glasson SS, Askew R, Sheppard B, Carito B, Blanchet T, Ma HL, Flannery CR, Peluso D, Kanki K, Yang Z, Majumdar MK, Morris EA: Deletion of active ADAMTS5 prevents cartilage degradation in a murine model of osteoarthritis. Nature 2005, 434:644-648

45. Stanton H, Rogerson FM, East CJ, Golub SB, Lawlor KE, Meeker CT, Little CB, Last K, Farmer PJ, Campbell IK, Fourie AM, Fosang AJ: ADAMTS5 is the major aggrecanase in mouse cartilage in vivo and in vitro. Nature 2005, 434:648-652

46. Takigawa M, Okada M, Takano T, Ohmae H, Sakuda M, Suzuki F: Studies on chondrocytes from mandibular condylar cartilage, nasal septal cartilage, and spheno-occipital synchondrosis in culture. I Morphology, growth, glycosaminoglycan synthesis, and responsiveness to bovine parathyroid hormone (1-34). J Dent Res 1984, 63:19-22

47. Darling EM, Athanasiou KA: Rapid phenotypic changes in passaged articular chondrocyte subpopulations. J Orthop Res 2005, 23:425-432

48. Benya PD, Shaffer JD: Dedifferentiated chondrocytes reexpress the differentiated collagen phenotype when cultured in agarose gels. Cell 1982, 30:215-224

49. Bock HC, Michaeli P, Bode C, Schultz W, Kresse H, Herken R, Miosge $\mathrm{N}$ : The small proteoglycans decorin and biglycan in human articular cartilage of late-stage osteoarthritis. Osteoarthritis Cartilage 2001, 9:654-663

50. Melrose J, Fuller ES, Roughley PJ, Smith MM, Kerr B, Hughes CE, Caterson B, Little CB: Fragmentation of decorin, biglycan, lumican and keratocan is elevated in degenerate human meniscus, knee and hip articular cartilages compared with age-matched macroscopically normal and control tissues. Arthritis Res Ther 2008, 10:R79

51. Cohn RD, van Erp C, Habashi JP, Soleimani AA, Klein EC, Lisi MT, Gamradt M, ap Rhys CM, Holm TM, Loeys BL, Ramirez F, Judge DP, Ward CW, Dietz HC: Angiotensin II type 1 receptor blockade attenuates TGF-beta-induced failure of muscle regeneration in multiple myopathic states. Nat Med 2007, 13:204-210

52. Neptune ER, Frischmeyer PA, Arking DE, Myers L, Bunton TE, Gayraud B, Ramirez F, Sakai LY, Dietz HC: Dysregulation of TGF-beta activation contributes to pathogenesis in Marfan syndrome. Nat Genet 2003, 33:407-411

53. Ng CM, Cheng A, Myers LA, Martinez-Murillo F, Jie C, Bedja D, Gabrielson KL, Hausladen JM, Mecham RP, Judge DP, Dietz HC: TGFbeta-dependent pathogenesis of mitral valve prolapse in a mouse model of Marfan syndrome. J Clin Invest 2004, 114:1586-1592

54. Border WA, Noble NA, Yamamoto T, Harper JR, Yamaguchi $Y$ Pierschbacher MD, Ruoslahti E: Natural inhibitor of transforming growth factor-beta protects against scarring in experimental kidney disease. Nature 1992, 360:361-364

55. Lorenzo P, Aspberg A, Onnerfjord P, Bayliss MT, Neame PJ, Heinegard D: Identification and characterization of asporin: a novel member of the leucine-rich repeat protein family closely related to decorin and biglycan. J Biol Chem 2001, 276:12201-12211

56. Blaney Davidson EN, Vitters EL, van der Kraan PM, van den Berg WB: Expression of transforming growth factor-beta (TGFbeta) and the TGFbeta signalling molecule SMAD-2P in spontaneous and instability-induced osteoarthritis: role in cartilage degradation, chondrogenesis and osteophyte formation. Ann Rheum Dis 2006, 65:1414-1421

57. Blaney Davidson EN, Scharstuhl A, Vitters EL, van der Kraan PM, van den Berg WB: Reduced transforming growth factor-beta signaling in cartilage of old mice: role in impaired repair capacity. Arthritis Res Ther 2005, 7:R1338-1347

58. Serra R, Johnson M, Filvaroff EH, LaBorde J, Sheehan DM, Derynck R, Moses HL: Expression of a truncated, kinase-defective TGFbeta type II receptor in mouse skeletal tissue promotes terminal chondrocyte differentiation and osteoarthritis. J Cell Biol 1997, 139:541-552

59. Wu Q, Kim KO, Sampson ER, Chen D, Awad H, O'Brien T, Puzas JE, Drissi H, Schwarz EM, O'Keefe RJ, Zuscik MJ, Rosier RN: Induction of an osteoarthritis-like phenotype and degradation of phosphorylated Smad3 by Smurf2 in transgenic mice. Arthritis Rheum 2008, 58:3132-3144

60. Yang X, Chen L, Xu X, Li C, Huang C, Deng CX: TGF-beta/Smad3 
signals repress chondrocyte hypertrophic differentiation and are required for maintaining articular cartilage. J Cell Biol 2001, 153:35-46

61. Sviri GE, Blumenfeld II, Livne E: Differential metabolic responses to local administration of TGF-beta and IGF-1 in temporomandibular joint cartilage of aged mice. Arch Gerontol Geriatr 2000, 31: 159-176

62. Pombo-Suarez M, Castano-Oreja MT, Calaza M, Gomez-Reino J, Gonzalez A: Differential upregulation of the three transforming growth factor beta isoforms in human osteoarthritic cartilage. Ann Rheum Dis 2009, 68:568-571

63. Fahlgren A, Andersson B, Messner K: TGF-beta1 as a prognostic factor in the process of early osteoarthrosis in the rabbit knee. Osteoarthritis Cartilage 2001, 9:195-202

64. Matsumoto T, Tojyo I, Kiga N, Hiraishi Y, Fujita S: Expression of ADAMTS- 5 in deformed human temporomandibular joint discs. Histol Histopathol 2008, 23:1485-1493

65. Lim WH, Toothman J, Miller JH, Tallents RH, Brouxhon SM, Olschowka ME, Kyrkanides S: IL-1beta inhibits TGFbeta in the temporomandibular joint. J Dent Res 2009, 88:557-562

66. Zhu M, Chen M, Zuscik M, Wu Q, Wang YJ, Rosier RN, O'Keefe RJ, Chen D: Inhibition of beta-catenin signaling in articular chondrocytes results in articular cartilage destruction. Arthritis Rheum 2008, 58:2053-2064 